Research Article

\title{
Seismic Behavior of a Novel Buckling-Restrained Steel Plate Shear Wall
}

\author{
Yang Li $\mathbb{D}^{1,2}$ Xiaofeng Zhao, ${ }^{1}$ Ping Tan $\mathbb{D}^{3,},{ }^{3,4,5}$ Fulin Zhou, ${ }^{1,4,5}$ and Jin Jiang $\mathbb{D}^{3,6}$ \\ ${ }^{1}$ College of Civil Engineering, Hunan University, Changsha 410082, China \\ ${ }^{2}$ Department of Civil Engineering and Transportation Engineering, Yellow River Conservancy Technical Institute, \\ Kaifeng 475004, China \\ ${ }^{3}$ School of Civil Engineering, Guangzhou University, Guangzhou 510405, China \\ ${ }^{4}$ Guangdong Provincial Key Laboratory of Earthquake Engineering and Advanced Technology, Guangzhou University, \\ Guangzhou 510405, China \\ ${ }^{5}$ Key Laboratory of Earthquake Resistance, Earthquake Mitigation and Structural Safety of the Ministry of Education, \\ Guangzhou University, Guangzhou 510405, China \\ ${ }^{6}$ Complex Steel Structure Research Center of Guangdong Province, Guangzhou University, Guangzhou 510405, China
}

Correspondence should be addressed to Ping Tan; ptan@gzhu.edu.cn

Received 17 February 2021; Revised 10 August 2021; Accepted 16 August 2021; Published 23 August 2021

Academic Editor: Jie Yang

Copyright (C) 2021 Yang Li et al. This is an open access article distributed under the Creative Commons Attribution License, which permits unrestricted use, distribution, and reproduction in any medium, provided the original work is properly cited.

In this study, in a novel buckling-restrained steel plate shear wall (BRSPSW) with out-of-plane deformation spaces, angle steel stiffeners have been installed so as to create gaps between the steel plate and the covering concrete slabs. A finite element model has been developed to analyse the effect of the gap. According to the finite element results, seismic performance of this novel BRSPSW has been tested under cyclic loading at the scale ratio of $1 / 3$. The failure pattern, hysteretic characteristics, skeleton curve, equivalent stiffness, ductility, and energy dissipation have all been systematically analysed. A stiffened steel plate shear wall (SPSW) has also been tested in order to determine the differences between these two steel shear walls in load-carrying capability and the function and significance of the gap. The test results show that the novel BRSPSW does not only significantly enhance the ultimate bearing capacity, stiffness, ductility, and accumulated energy dissipation of the SPSW but also keep the steel plate basically intact at the end of the test. This can be attributed to the existence of the gaps between the infilled steel plate and the covering concrete slabs. The hysteretic characteristics and the strength and deformation characteristics of this novel BRSPSW have been simulated by using the finite element model, and the test results are in good agreement with the finite element results. Hence, the BRSPSW is an excellent steel plate shear wall to be used in high rise structure to resist horizontal loadings.

\section{Introduction}

Among the frequently used energy dissipation devices, steel plate shear walls (SPSWs) have been widely used in steel and concrete-framed structures [1]. In recent decades, the SPSW has been experimentally and numerically investigated, and it has been found to be a robust and effective lateral loadresisting system exhibiting high lateral bearing capacity, good ductility, and stable energy dissipation performance $[2,3]$. Compared with the concrete shear wall, SPSWs have the following advantages: (1) larger initial stiffness and bearing capacity, which gives more effective control to the lateral stiffness of the structure system; (2) better ductility and more stable energy dissipation performance, which improve the seismic performance of the structure; and (3) smaller self-weight of the structure, which reduces the size and cost of the foundation. However, a thin steel plate is prone to buckle, which has undesirable effects on the mechanical performance of the shear wall $[4,5]$. A number of methods have been proposed to restrain the buckling of the steel plates, such as applying different forms of stiffeners [6-8], providing vertical slits in the steel plate [9-11], lowering the yield point [12-14], opening holes [15, 16], adopting corrugated plate web $[17,18]$, or using steel plate 
shear wall with self-centering energy dissipation braces [19-21], but none of them have the ideal restraint effect.

In order to prevent an infilled steel plate from buckling at an early stage of loading, the buckling-restrained steel plate shear wall (BRSPSW) was originally proposed by AstanehAsl as a new lateral loading resisting system [22]. So far, many other types of BRSPSWs with various structural configurations have been proposed and have shown high performance on ductility, initial stiffness, shear resistance, and energy absorption. Zhao and Astaneh-Asl [23] studied the mechanical performance of the composite steel plate shear wall connected with the frame on four sides and pointed out that the premature buckling of the infilled steel plate can be prevented by the covering concrete slabs on both sides of the infilled steel plate to improve its mechanical performance. On this basis, Guo et al. [24, 25] put forward that the diameter of bolt holes in the covering concrete slabs should be larger than the diameter of the bolts, so that the bolts have enough sliding space to ensure that the covering concrete slabs do not bear horizontal forces and only serve as a prevention of the infilled steel plate. Guo et al. [26, 27] put forward the steel plate concrete composite shear wall, of which the infilled steel plate is only connected with the frame beam to avoid premature failure of the frame column. The layout of the steel plate concrete composite shear wall is flexible, making it conducive to open doors and windows, as well as adjusting the structural rigidity. Lu et al. [28] put forward I-shaped buckling-restrained steel plate shear wall with large aspect ratio. Test results show that the bucklingrestrained steel plate shear wall with I-shaped structure has good seismic performance, and it is not easy to cause steel plate tearing failure due to stress concentration at the support. Liu et al. [29] theoretically studied the mechanical behavior of buckling-restrained steel plate shear walls (BRSPSWs) with two-side connections and various heightto-width ratios. The results show that the steel plate with a small height-to-width ratio $(<1.5)$ has a middle shearing region and boundary restraining regions at the left and right edges with a width of $1 / 3$ of the height of steel plate. Du et al. [30] and $\mathrm{Yu}$ et al. [31] put forward the multistiffener buckling-restrained steel plate shear wall. Test results show that it can effectively alleviate the initial geometric imperfections of the steel plate to avoid the overall buckling of the steel plate and improve the pinch phenomenon of the hysteretic curve. Wei et al. [32, 33] put forward a partially connected buckling-restrained steel plate shear wall, which has good ductility and energy dissipation performance. The ultimate bearing capacity and hysteretic performance of the partially connected buckling-restrained steel plate shear wall increase with the increase of concrete cover thickness. Jin et al. $[34,35]$ put forward the buckling-restrained steel plate shear wall with inclined slots. By setting different forms of inclined slots on the steel plate, the energy of the bucklingrestrained steel plate shear wall with inclined slots can be consumed through the tension and compression deformation of steel strips between the slots.

However, as shown in Figure 1, the corners of the infilled steel plate are commonly torn off at the end of the tests. Even though the surface of the infilled steel plate is basically intact, the cracks at the corners can result in a connection failure between the infilled steel plate and the surrounding steel connecting plates, thereby reducing the structural carrying capacity.

To solve the cracking problem of the corners of the traditional buckling-restrained steel plate shear walls, Tan [36] put forward a novel BRSPSW, which provided gaps between the infilled steel plate and the covering concrete slabs so as to ease the stress concentration of the infilled steel plate at the four corners. In this study, this novel BRSPSW with gaps between the infilled steel plate and the covering concrete slabs has been investigated by applying angle steel stiffeners to form the gaps. The gap thickness can be easily controlled by changing the thickness of the angle steels, which greatly improves the construction precision of the gaps. A quasi-static cyclic test has been conducted on the novel BRSPSW to systematically analyse its hysteretic characteristics, skeleton curve, equivalent stiffness, ductility, and energy dissipation. A stiffened flat SPSW has also been tested so that the differences between these two types of steel shear walls in load-carrying capability can be compared, and the function and significance of the gap can be assessed.

\section{Construction of Novel BRSPSW}

The construction of the novel BRSPSW is shown in Figure 2, which has the following structural characteristics: (1) the gaps are formed by installing angle steel stiffeners, and the gap thickness is equal to the thickness of angle steels; (2) a two-sided connection is used, which means that the infilled steel plate is only connected to the top and bottom beams; and (3) the stiffeners are installed at the left and the right edges of the infilled steel plate. The covering concrete slabs, angle steel stiffeners, and infilled steel plate are fixed by highstrength bolts. Further, the left and right edges of the infilled steel plate and the edge of angle steel are welded. The welded seams can be seen in Figure 2(a).

\section{Gap Thickness}

3.1. Finite Element Model. In this study, in order to determine the suitable size of the gaps between the infilled steel plate and the covering concrete slabs, a finite element (FE) model has been developed using the finite element analysis software ABAQUS/Standard to perform push-over analysis. To guide the manufacturing of the specimens directly, a onethird scaled one-bay one-story FE model has been developed. It is of the same construction as that of the novel BRSPSW and the same size as that of the following experiment specimen. In the selection of scale, considering that the smaller specimen, the worse accuracy of the test, and referring to the specimens' scale selected by a large number of scholars for the steel plate shear wall test, the one-third scale is a common and reasonable choice, which can take into account the accuracy of the test and the limitations of the test space and loading capacity of the test setup. The dimensions of the components in the FE model are shown in Table 1. Since the thickness and stiffness of the connecting plates and the fish plates are much larger than the infilled 


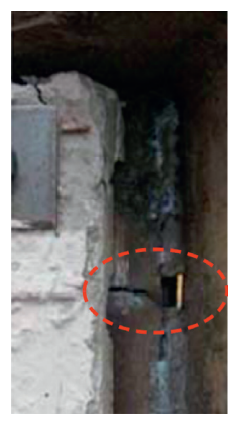

(a)

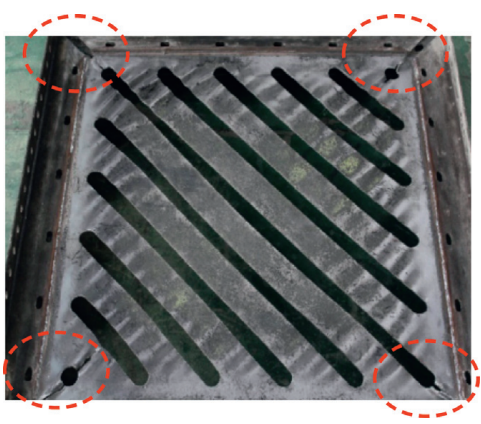

(b)

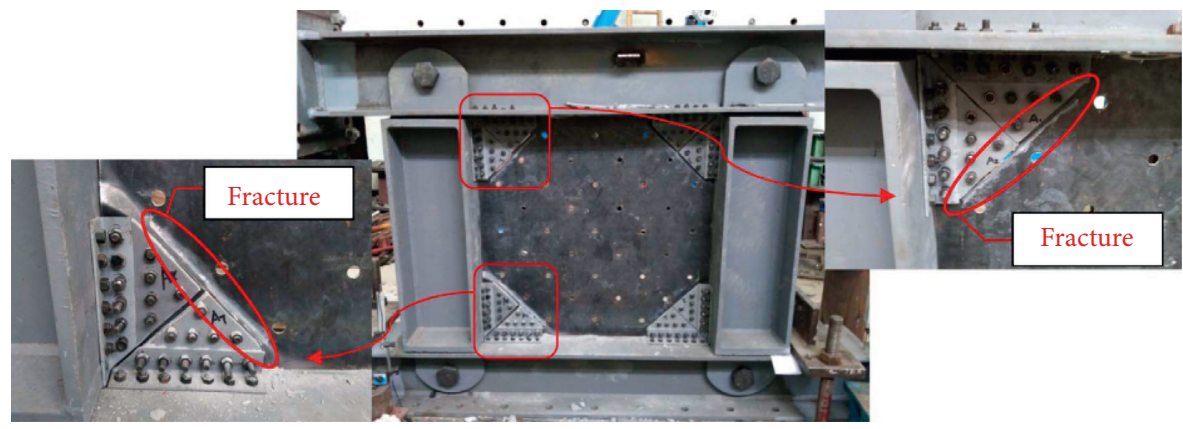

(c)

FIGURE 1: Infilled steel plate torn off at corners. (a) Result of CSPSW (Guo et al. [26]). (b) Result of test specimen (Jin et al. [34]). (c) Result of P-SWSW1 (Wei et al. [33]).

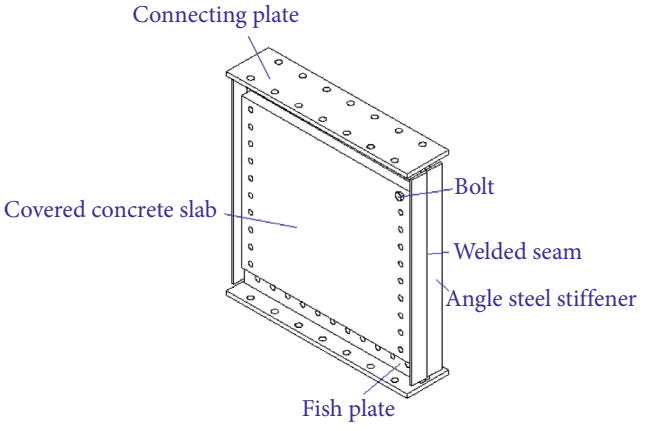

(a)

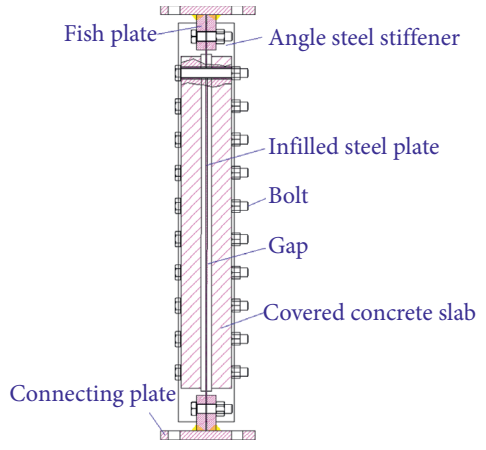

(b)

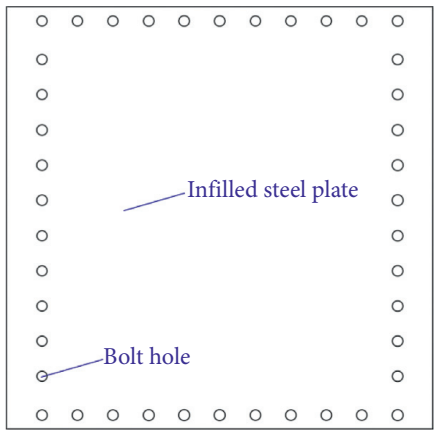

(c)

FIGURE 2: Construction of novel BRSPSW. (a) 3D perspective. (b) Side profile. (c) Infilled steel plate.

TABle 1: Dimensions of the components in the finite element model.

\begin{tabular}{lccc}
\hline No. & Component & Section $(\mathrm{mm})$ & Length $(\mathrm{mm})$ \\
\hline 1 & Angle steel stiffener & $100 \times 10$ & 920 \\
2 & Infilled steel plate & $920 \times 3$ & 900 \\
3 & Concrete slab & $820 \times 740 \times 45$ \\
\hline
\end{tabular}

plate, the deformation of the FE model is mainly manifested in the infilled plate. To simplify the FE model, the connecting plates and the fish plates have not been included in the FE model. Figure 3 shows the FE model. The S4R shell element has been used to model the infilled steel plate and the angle steel stiffeners. The C3D8R solid element and the T3D2 truss element have been used to model the covering concrete slabs

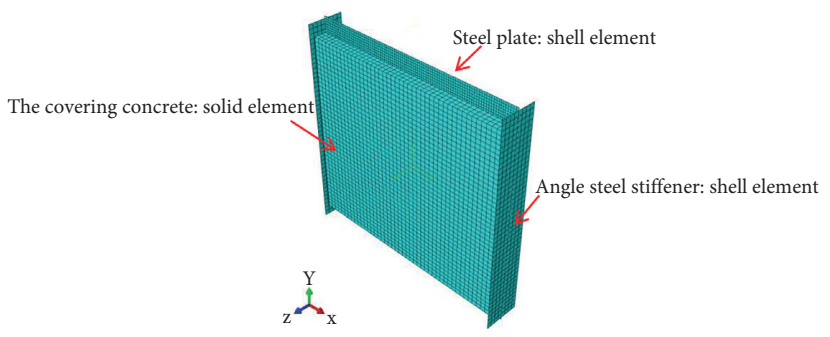

FIgURE 3: Finite element model of the novel BRSPSW.

and the embedded reinforcement, respectively. The diameter of $10 \mathrm{~mm}$ and the double-layer double-way arrangement with the spacing of $100 \mathrm{~mm}$ have been used for the embedded reinforcement. The contact pair interaction has been 
used to model the contact and interaction between the covering concrete slabs and the infilled steel plate. The normal contact behavior between the covering concrete slabs and the infilled steel plate has been modelled using the "hard" contact. When the surfaces of the covering concrete slabs and the infilled steel plate are in contact, there is a contact pressure between them. When the surfaces are separated, the contact pressure is zero. A "friction" model has been used to model the tangential behavior across the interface between the infilled steel plate and the covering concrete slabs. Wei et al. [32] analysed the mechanical behavior of the partially connected buckling-restrained steel plate shear wall with different friction coefficients. The analysis results showed that when the friction coefficient between the infilled steel plate and the covered concrete slabs increased from 0 to 0.6 , the bearing capacity of the partially connected buckling-restrained steel plate shear wall was almost unchanged, which means the influence of friction coefficient can be ignored. Therefore, a friction coefficient of 0.3 has been used in the model to reflect the friction behavior between infilled steel plate and the covered concrete slabs objectively. The method of coupling out-of-plane degree of freedom has been used to model the bolts.

Figure 4 shows the constitutive law of steel. The angle steel stiffeners are made of Q345 steel with $E_{s}=210 \mathrm{GPa}$ and $f_{y}=345 \mathrm{MPa}$. The infilled steel plate is made of Q235 steel with $E_{s}=210 \mathrm{GPa}$ and $f_{y}=235 \mathrm{MPa}$. The embedded reinforcement is made of HRB335 with $E_{s}=210 \mathrm{GPa}$ and $f_{y}=335 \mathrm{MPa}$. Poisson's ratio of the steel material is 0.3 . The concrete damaged plasticity model in ABAQUS has been used to model the concrete material. The covering concrete slabs are made of C30 concrete with $E_{s}=30 \mathrm{GPa}$ and $f_{c}^{\prime}=30 \mathrm{MPa}$, where $f_{c}^{\prime}$ is the cylinder strength of concrete. Poisson's ratio of concrete material is 0.2 . The plastic coefficients of the concrete material are shown in Table 2.

In this study, an initial geometric imperfection pattern corresponding to the first buckling mode of the steel plate has been assumed in the FE model so as to initiate the out-ofplane deflection, in which the peak lateral deflection is equal to the physical gap between the infilled steel plate and the covering concrete slabs. The elastic buckling analysis has been carried out first on the infilled steel plate without covering the concrete slabs in order to obtain the imperfection shape. Then, a monotonic pushover displacement is applied. As such, the novel BRSPSW is subjected to the shear force up to $2 \%$ target drift.

3.2. Effect of the Gap. In order to determine the effect of the gap on the mechanical performance of the novel BRSPSW, a series of the novel BRSPSW FE models have been used to simulate different gap thicknesses. Due to the installation error and initial geometric imperfections, there is always an uneven gap between the infilled steel plate and the covering concrete slabs. Even though the bolts are tightened, there is still a gap of $2 \mathrm{~mm}$ to $4 \mathrm{~mm}$ between the infilled steel plate and the cover concrete slabs. As a consequence, the thickness of the gaps between the infilled steel plate and the covering concrete slabs varies from $5.0 \mathrm{~mm}$ to $15 \mathrm{~mm}$. Further, a gap

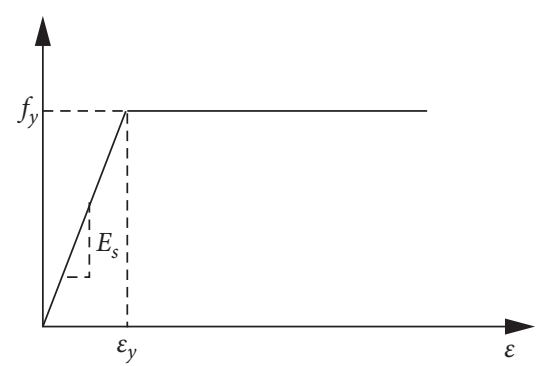

Figure 4: Constitutive behaviors of steel.

Table 2: Plastic coefficients of concrete.

\begin{tabular}{lcccc}
\hline$\theta\left(^{\circ}\right)$ & $\varepsilon$ & $\sigma_{b 0} / \sigma_{c 0}$ & $k_{c}$ & $\gamma$ \\
\hline 30 & 0.1 & 1.16 & 0.6667 & 0.005 \\
\hline
\end{tabular}

$\theta$ is the dilation angle; $\varepsilon$ is the eccentricity; $\sigma_{b 0}$ is the initial equivalent biaxial compression strength; $\sigma_{c 0}$ is the initial uniaxial compression strength; $k_{c}$ is the stress ratio; and $\gamma$ is the viscosity parameter.

thickness of $20 \mathrm{~mm}$ and a flat steel plate have also been modelled. With the increase of the gap thickness, the corner stress decreases gradually, which can be seen in Table 3 . Figure 5 shows the load-displacement curves of the novel BRSPSW with different gap thicknesses and with the flat steel plate. A significant change in the mechanical performance of the novel BRSPSW occurs when the gap thickness is between $7 \mathrm{~mm}$ and $13 \mathrm{~mm}$. Due to the increase in the gap thickness, the constraint effect provided by the covering concrete slabs is delayed and an out-of-plane deformation space is formed. When the out-of-plane deformation of the infilled steel plate is the same as the gap thickness, the covering concrete slabs begin to restrain the further out-ofplane deformation of the infilled steel plate, which eases the stress concentration of the four corners of the infilled steel plate. If the gap thickness is too large, such as larger than $13 \mathrm{~mm}$, the covering concrete slabs cannot provide the timely constraint effect. Hence, the bearing capacity of the novel BRSPSW decreases. Therefore, in this study, the suitable gap thickness is between $7 \mathrm{~mm}$ and $13 \mathrm{~mm}$.

\section{Experimental Programs}

4.1. Test Specimens. In order to investigate the hysteretic performance of the novel BRSPSW and the effect of the gap between the infilled steel plate and the covering concrete slabs on the hysteretic performance, two specimens (i.e., one SPSW specimen and one BRSPSW specimen) have been fabricated and tested under the quasi-static cyclic loading. Because of the limitation of loading capacity of the test setup, two one-third scaled one-bay one-story specimens were selected for the study, which can also save test space. The thickness of the steel plate used in the two specimens is $3 \mathrm{~mm}$. The size of the infilled plates is $920 \mathrm{~mm} \times 900 \mathrm{~mm}$ for both specimens. For the BRSPSW specimen, the reinforcement in the covering concrete slabs is made of HRB335 with the diameter of $10 \mathrm{~mm}$. Based on the analysis results in Section 3.2, a $10 \mathrm{~mm}$ gap thickness between the infilled steel plate and the covering concrete slabs has been chosen for 
TABLE 3: Stress at the top left corner.

\begin{tabular}{lc}
\hline Gap thickness $(\mathrm{mm})$ & Stress at the top left corner $(\mathrm{MPa})$ \\
\hline 5 & 236.3 \\
6 & 236.0 \\
7 & 235.9 \\
8 & 235.9 \\
9 & 235.7 \\
10 & 235.5 \\
11 & 235.0 \\
12 & 234.6 \\
13 & 234.3 \\
14 & 234.0 \\
15 & 233.9 \\
20 & 233.7 \\
Flat steel plate & 233.7 \\
\hline
\end{tabular}

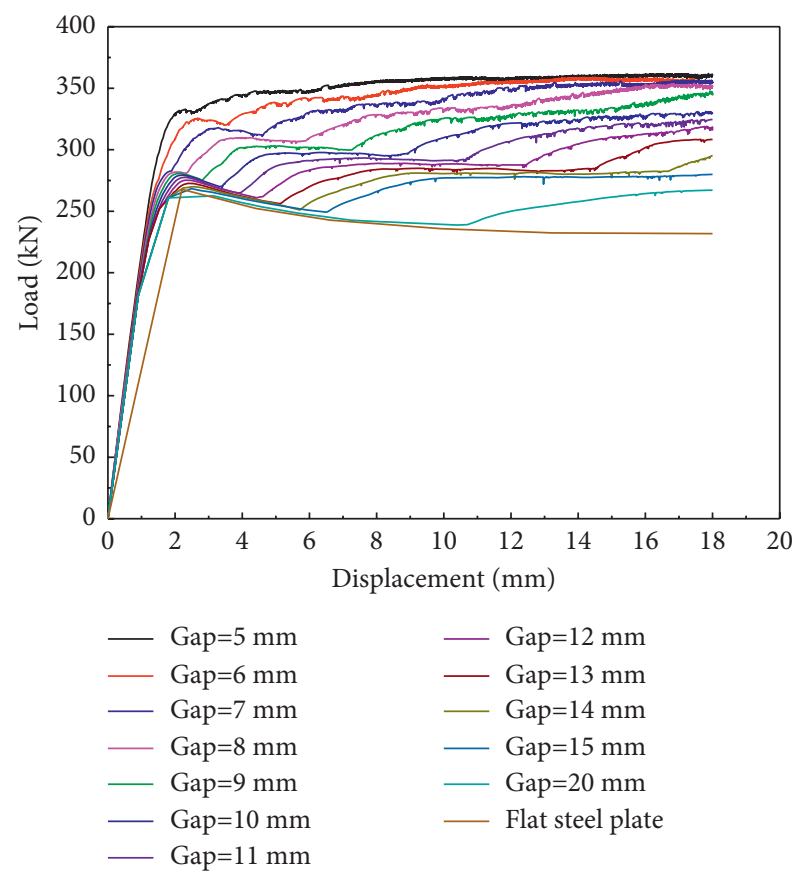

FIGURE 5: Load-displacement curves of the novel BRSPSW with different gap thicknesses and with the flat steel plate.

convenient construction. The detailed configurations of the two specimens are shown in Figures 6 and 7. The detailed dimensions of the two specimens are shown in Tables 4 and 5.

4.2. Test Setup. Figure 8 shows the detailed test setup. In this study, a $300 \mathrm{t}$ dynamic load electrohydraulic servo testing machine with the maximum loading speed of $500 \mathrm{~mm} / \mathrm{s}$ has been used. The testbed is clamped with the grounded outside infinite stiffness frame. Using an MTS hydraulic servo actuator, the horizontal reciprocating loading is applied to the specimens. The hydraulic servo actuator creates the constraints and the loading conditions of the two specimens as follows:
At the top: The top and outside frame beam of the specimen is fixed, thereby creating the fixed end condition.

At the bottom: The bottom of the specimen and the four directional rolling guide rails are connected. The guide rail can move freely in the horizontal direction only, thereby creating the condition of a mobile terminal.

At the loading end: The bottom end of the hydraulic servo actuator is connected to the reaction wall, while the other end of the actuator is connected to the four directional rolling guide rails, in which the horizontal loading is applied to the specimen.

4.3. Instrumentation. In order to obtain the precise hysteresis curves of the specimens, a displacement transducer in the reversed side of specimen has been used as a third-party feedback control displacement meter. The range and accuracy of the displacement transducer are $\pm 150 \mathrm{~mm}$ and $0.01 \mathrm{~mm}$, respectively. The layouts of the displacement meter are the same in both specimens, as shown in Figure 9.

4.4. Initial Imperfection of Steel Plate. The initial geometric imperfection of the steel plate can affect the buckling behavior of the SPSW specimen. As such, the plate's initial out-of-plane deflection has been measured carefully using a laser scanner prior to the test. For the SPSW specimen, prior to the test, the initial maximum out-of-plane displacement of the steel plate was $1.2 \mathrm{~mm}$, which was about $1.33 / 1000$ of the height of the steel plate. This satisfies the requirement given in Chinese code for acceptance of construction quality of steel structures (GB 50205-2001 [37]) which states that the initial out-of-plane imperfection should not be more than $1.5 / 1000$ of the plate's height. For the BRSPSW specimen, the infilled steel plate was covered by the concrete slabs. Hence, the initial maximum out-of-plane displacement of the infilled steel plate could not be measured. Since the two infilled steel plates were manufactured in the same batch and installed by the same workers, the initial out-of-plane imperfection of the steel plate in the BRSPSW specimen has been assumed to satisfy the requirement given in GB 502052001 [37].

4.5. Loading Procedure. In accordance with the Chinese specification for seismic test of buildings (JGJ/T 101-2015 [38]), the displacement control method has been used to generate the horizontal low cyclic loading through triangular waves. The lateral cyclic loading used in the tests is illustrated in Figure 10. The amplitudes of the enforced horizontal displacement are $0.5 \mathrm{~mm}, 1 \mathrm{~mm}, 1.5 \mathrm{~mm}, 2 \mathrm{~mm}, 4 \mathrm{~mm}$, $8 \mathrm{~mm}, 12 \mathrm{~mm}, 16 \mathrm{~mm}, 24 \mathrm{~mm}, 30 \mathrm{~mm}, 38 \mathrm{~mm}, 44 \mathrm{~mm}$, and $52 \mathrm{~mm}$. The loading frequency is $0.02 \mathrm{~Hz}$. 


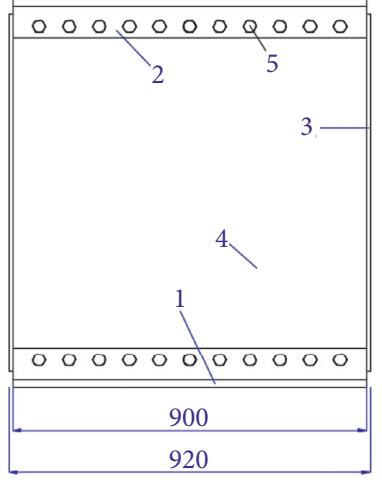

(a)
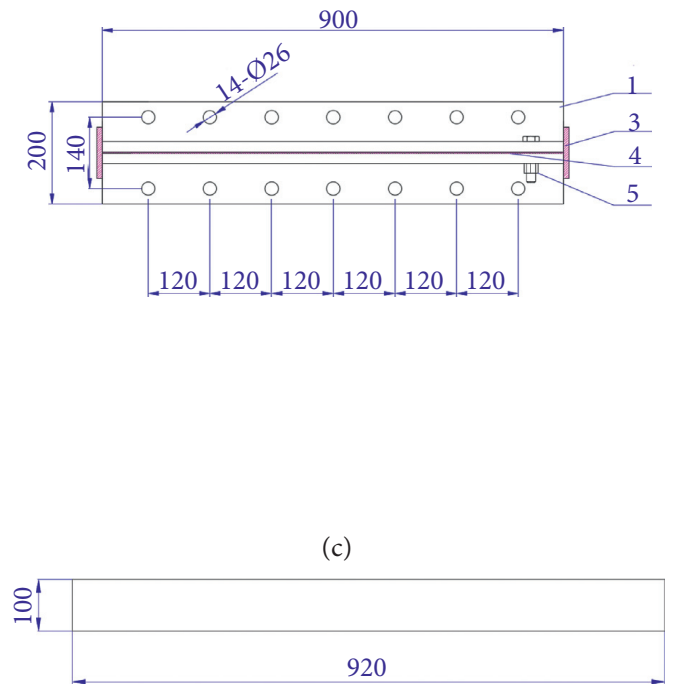

(e)

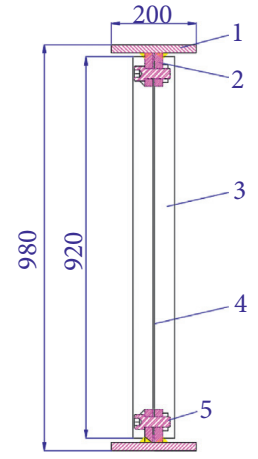

(b)

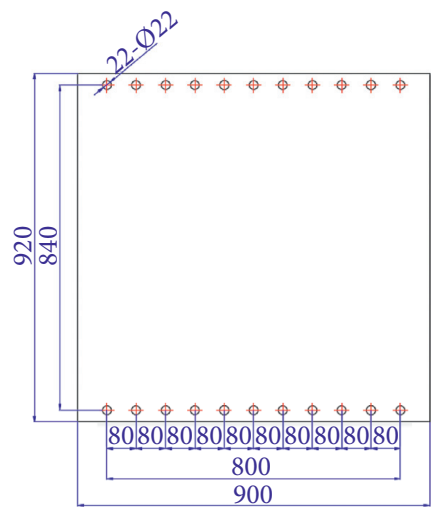

(d)

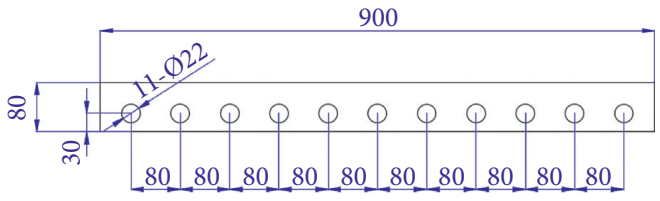

(f)

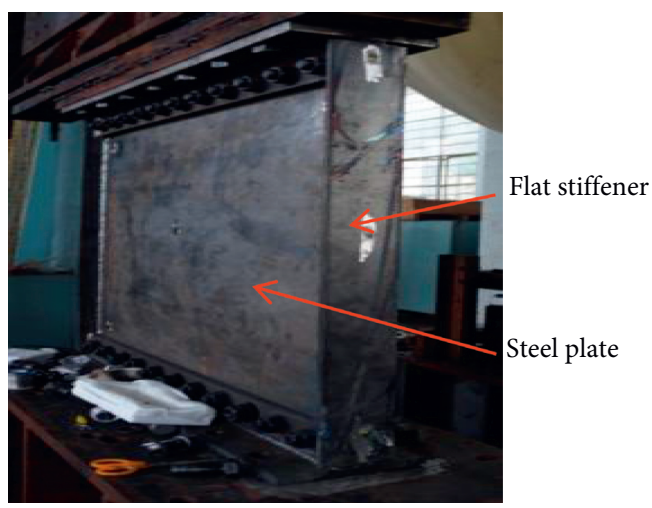

(g)

FIgure 6: Construction of SPSW specimen. (a) Plan. (b) Side profile. (c) Top profile. (d) Infilled steel plate. (e) Flat stiffener. (f) Fish plate. (g) Photograph of SPSW specimen.

4.6. Material Tests. The steel plates in the test specimens are made of Q235 steel. The flat stiffeners and angle steel stiffeners are made of Q345 steel. Three steel samples have been prepared from the steel plate, and three other steel samples have been prepared from the stiffener. Using the material tests, the material properties of the steel plates and the stiffeners have been determined and they are shown in Table 6. All the bolts used in the test specimens have a strength grade of 8.8 , where the nominal ultimate strength, $f_{u}$, and yield strength, $f_{y}$, are assumed to be $800 \mathrm{MPa}$ and $640 \mathrm{MPa}$, respectively. The concrete used to precast the concrete slabs has a designed strength grade of C30. Three 


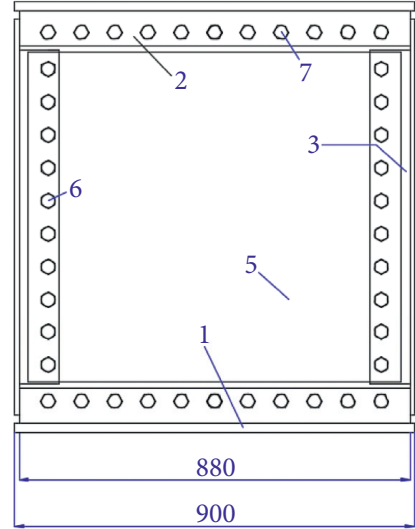

(a)

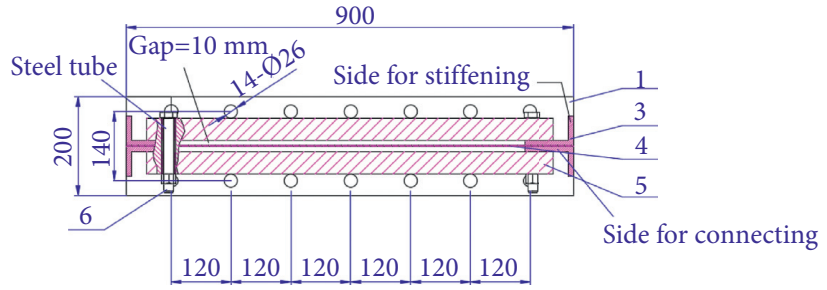

(c)

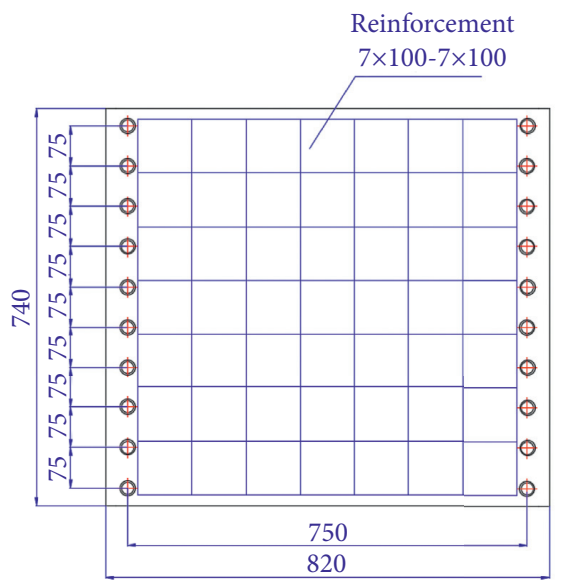

(e)

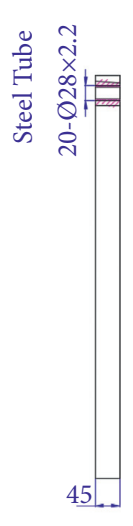

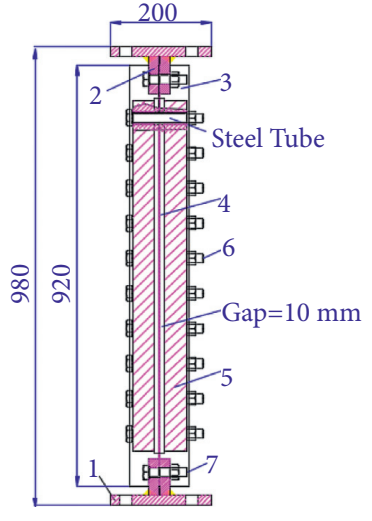

(b)

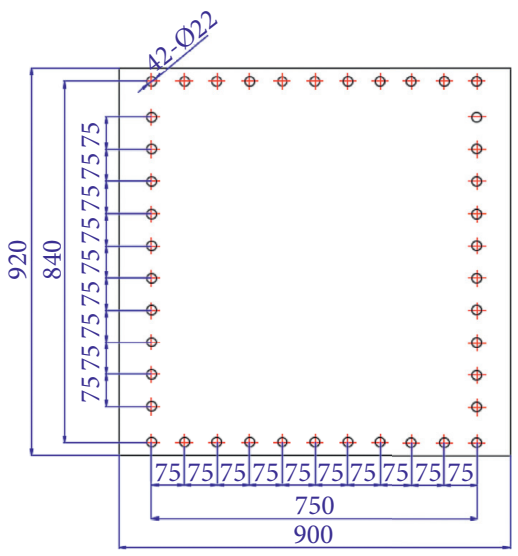

(d)

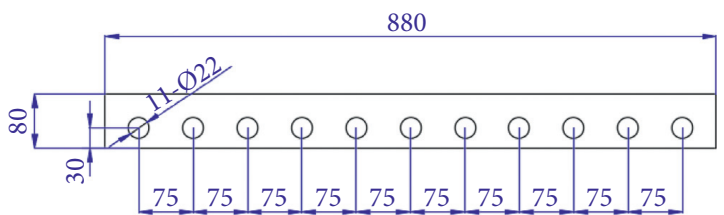

(f)

FIgure 7: Continued. 


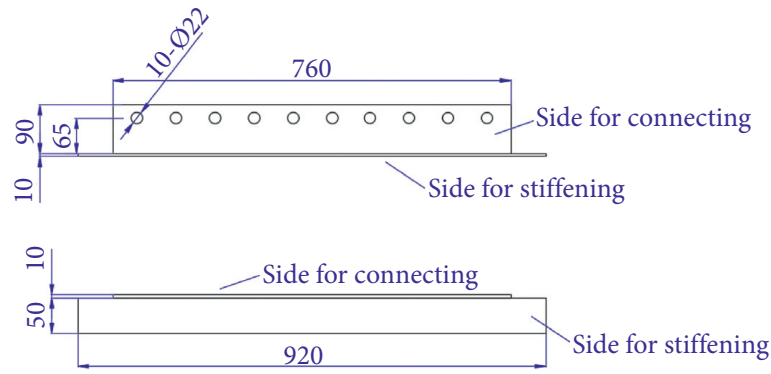

(g)

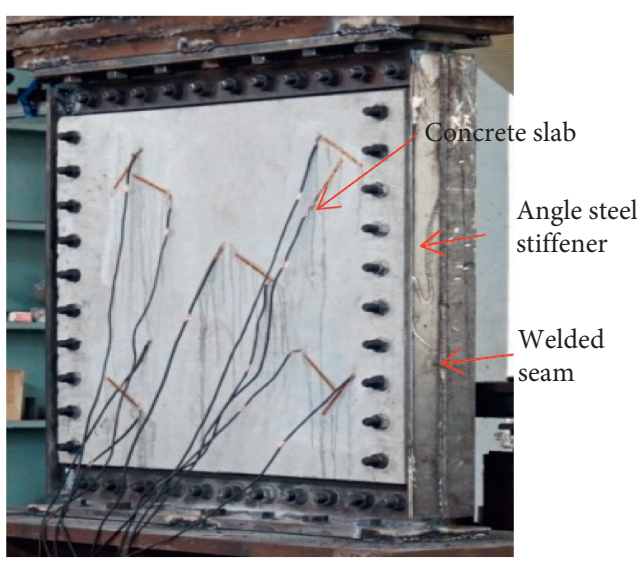

(h)

Figure 7: Construction of BRSPSW specimen. (a) Plan. (b) Side profile. (c) Top profile. (d) Infilled steel plate. (e) Concrete slab. (f) Fish plate. (g) Angle steel stiffener. (h) Photograph of BRSPSW specimen.

TABLE 4: Components of SPSW specimen.

\begin{tabular}{|c|c|c|c|c|}
\hline No. & Component & Section $(\mathrm{mm})$ & Length (mm) & Quantity \\
\hline 1 & Connecting plate & $200 \times 20$ & 900 & 2 \\
\hline 2 & Fish plate & $80 \times 20$ & 900 & 4 \\
\hline 3 & Flat stiffener & $100 \times 10$ & 920 & 2 \\
\hline 4 & Infilled steel plate & $920 \times 3$ & 900 & 1 \\
\hline 5 & High-strength bolt & \multicolumn{2}{|c|}{ Grade $8.8 \mathrm{M} 20 \times 80$} & 22 \\
\hline
\end{tabular}

TABLE 5: Components of BRSPSW specimen.

\begin{tabular}{|c|c|c|c|c|c|}
\hline No. & Component & & Section $(\mathrm{mm})$ & Length $(\mathrm{mm})$ & Quantity \\
\hline 1 & Connecting plate & & $200 \times 20$ & 900 & 2 \\
\hline 2 & Fish plate & & $80 \times 20$ & 880 & 4 \\
\hline & & Side for stiffening & $50 \times 10$ & 920 & 4 \\
\hline 3 & Angle steel stiffener & Side for connecting & $90 \times 10$ & 760 & 4 \\
\hline 4 & Infilled plate & & $920 \times 3$ & 900 & 1 \\
\hline 5 & Concrete slab & C30 & \multicolumn{2}{|c|}{$820 \times 740 \times 45$} & 2 \\
\hline 6 & High-strength bolt-B1 & & \multicolumn{2}{|c|}{ Grade $8.8 \mathrm{M} 20 \times 150$} & 20 \\
\hline 7 & High-strength bolt-B2 & & \multicolumn{2}{|c|}{ Grade $8.8 \mathrm{M} 20 \times 80$} & 22 \\
\hline
\end{tabular}

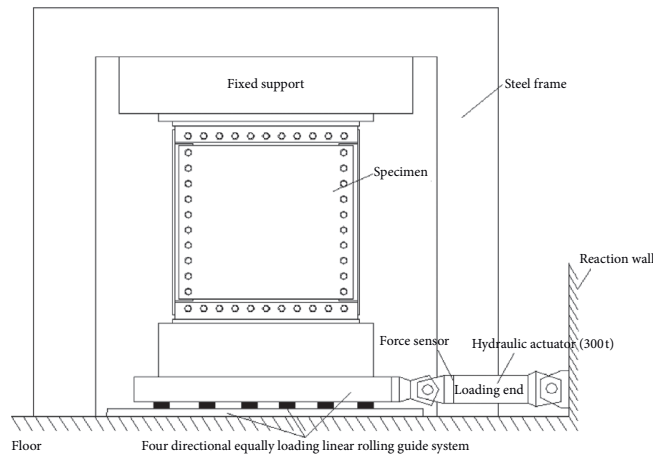

(a)

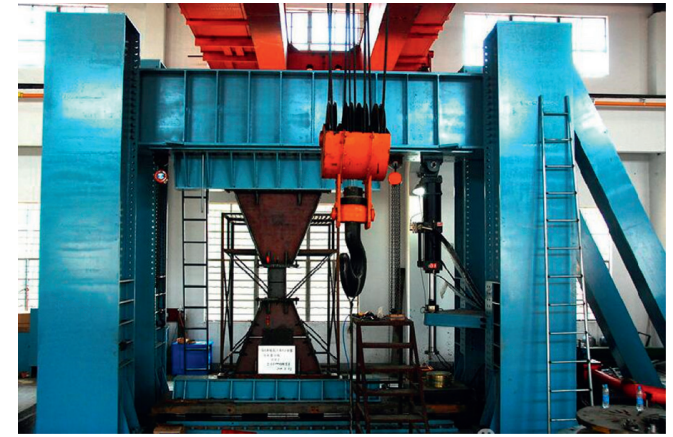

(b)

FIGURE 8: Test setup. (a) Schematic diagram of loading device. (b) Loading system. 


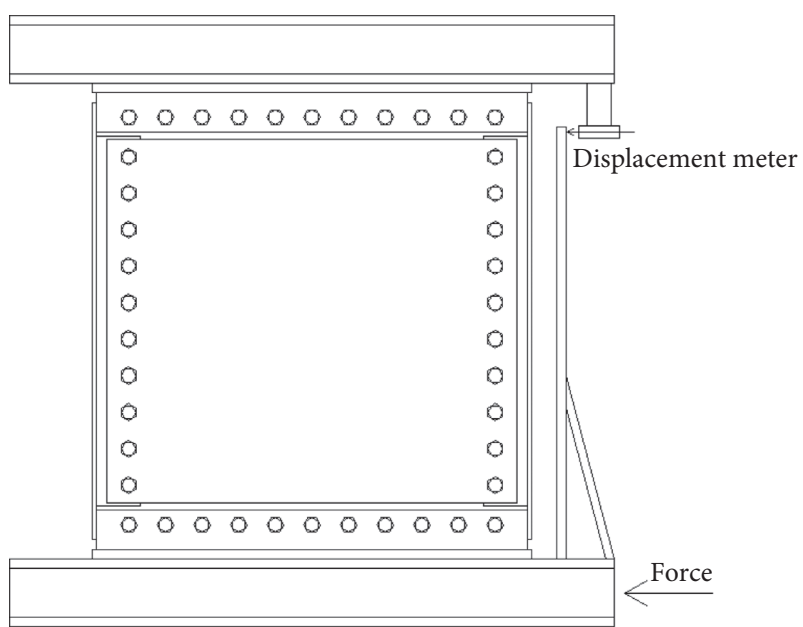

(a)

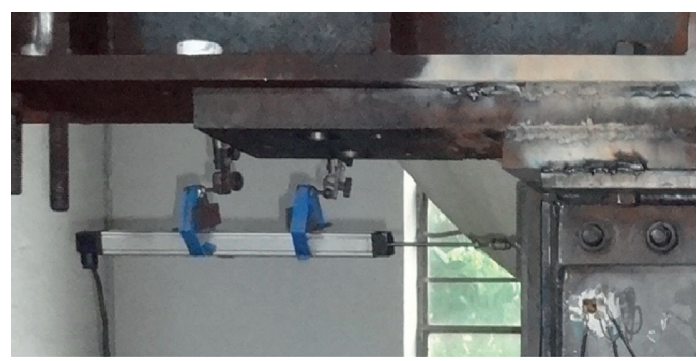

(b)

Figure 9: Layout of displacement meter (reversed side). (a) Schematic diagram of displacement meter. (b) Photograph of displacement meter.

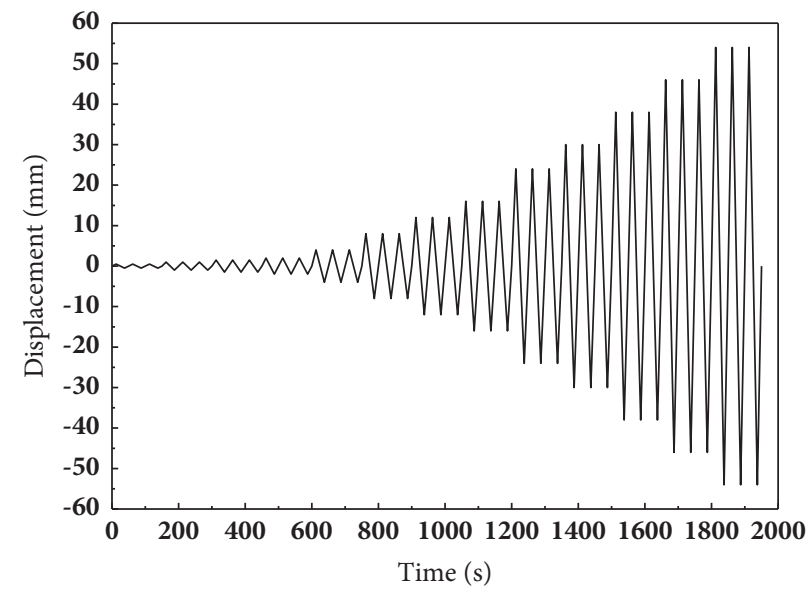

FIGURE 10: Loading program.

TABLE 6: Material properties of steel.

\begin{tabular}{lcccc}
\hline Name of sample & Nominal thickness $t(\mathrm{~mm})$ & Yield strength $f_{y}\left(\mathrm{~N} / \mathrm{mm}^{2}\right)$ & Ultimate strength $f_{u}\left(\mathrm{~N} / \mathrm{mm}^{2}\right)$ & Elongation $\sigma_{h}(\%)$ \\
\hline Steel plate & 3 & 225 & 398 & 45 \\
Stiffener & 10 & 354 & 533 & 32 \\
\hline
\end{tabular}

concrete cubes with a dimension of $150 \mathrm{~mm}$ have been made and maintained under the same conditions as that of the concrete slabs. The standard concrete compressive strength measured by the axial compression test is $33.75 \mathrm{~N} / \mathrm{mm}^{2}$.

\section{Test Phenomena and Destruction Form}

5.1. SPSW. During the whole loading period, the SPSW specimen showed the processes in which the buckling tension fields occurred and developed alternately in the front and back outside space of the steel plate. Each conversion of buckling tension fields from one side to the other side of the steel plate was accompanied with a high decibel "clang" sound. When the loading displacement of the SPSW specimen was $2 \mathrm{~mm}$, the steel plate formed one main tension field in the diagonal direction, as shown in Figure 11(a). When the displacement increased to $8 \mathrm{~mm}$, two small buckling waves appeared on both sides of the main tension field, as shown in Figure 11(b). As the displacement continued to increase to $24 \mathrm{~mm}$, the tension fields were developing continuously. The two small buckling waves expanded gradually to become two large secondary tension fields, in which one end was near the top or bottom of the beam, and the other end was near the stiffener, as shown in Figure 11(c). When the displacement was $30 \mathrm{~mm}$, the secondary tension fields continued to expand. The secondary tension fields were mainly dependent on the anchorage effect of the stiffeners. As shown in Figure 11(d), two stiffeners are bending inward with the increased tensile force in the steel plate. 


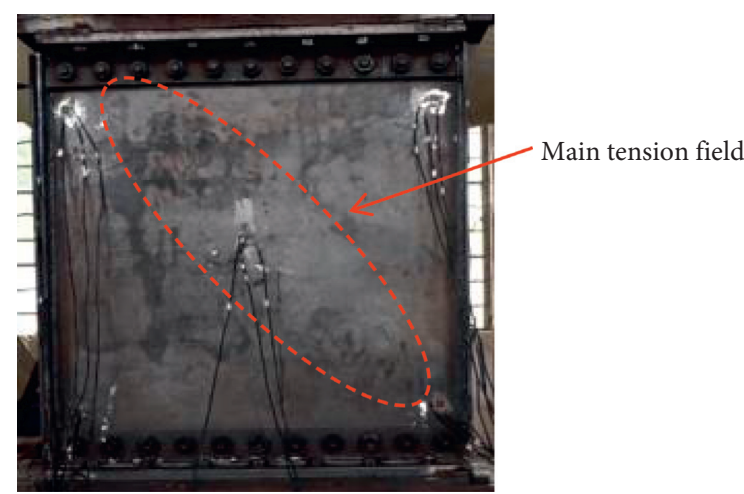

(a)

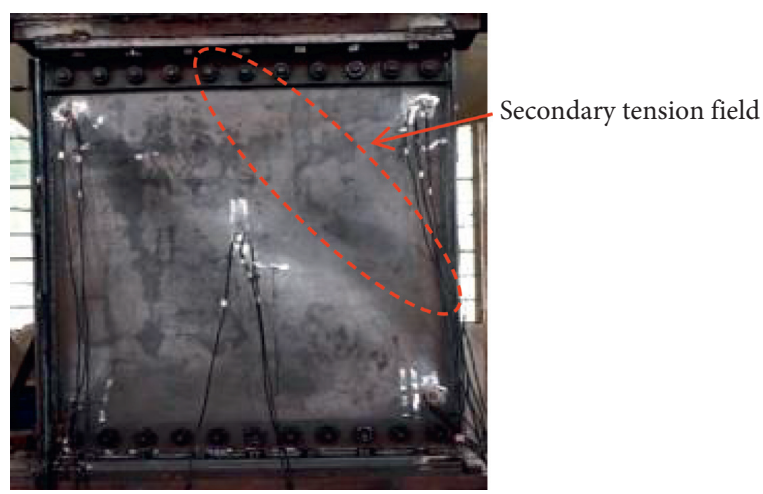

(c)

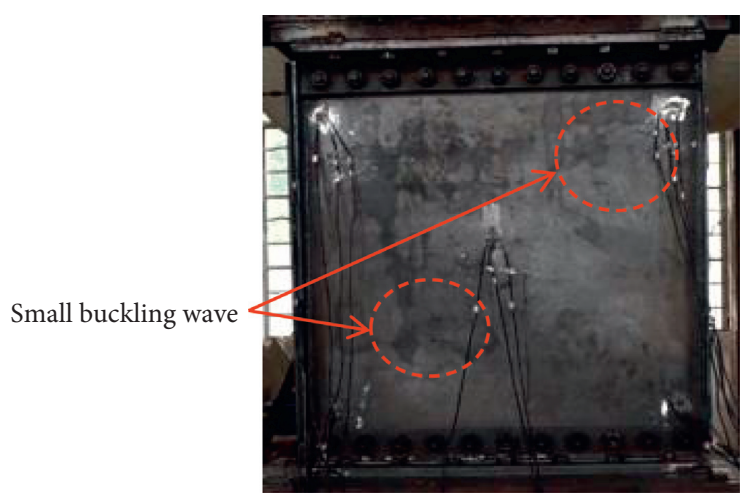

(b)

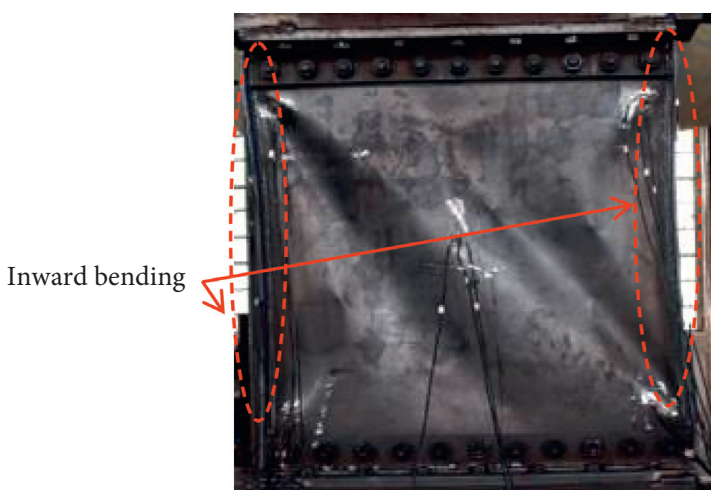

(d)

FIGURE 11: Deformation of SPSW specimen under different loading displacements. (a) $2 \mathrm{~mm}$. (b) $8 \mathrm{~mm}$. (c) $24 \mathrm{~mm}$. (d) $30 \mathrm{~mm}$.

The out-of-plane deformation of the steel plate could not be fully recovered even after it was completely uninstalled. As shown in Figure 12(a), there are five obvious half waves on the steel plate surface, of which the maximum residual out-of-plane deformation was $60 \mathrm{~mm}$. The final destruction form of the buckling wave was between the overall buckling and the local buckling. There were seven tearing cracks on the surface of the steel plate, all of which were located at the junction of the buckling half waves of the steel plate. Among all the cracks, the length of Crack 1 is longer than $120 \mathrm{~mm}$, while Cracks 2, 3, and 4 are obvious cross-cracks. Further, as shown in Figure 12(b), apart from the cracks on the surface of the steel plate, there is one tearing crack on the bottom right corner, and the length of this crack is close to $150 \mathrm{~mm}$. As shown in Figure 12(c), the inward bending deformation of the stiffener is very serious, of which the maximum deformation is $40 \mathrm{~mm}$.

5.2. BRSPSW. During each loading and unloading process, when the buckling waves were transformed, there was a whisper made by friction and the sound "dong" made by the impact between the infilled steel plate and the covering concrete slabs. With the increasing number of bolts, there was a "clang" sound when the bolt slipped during the whole loading process. When the loading displacement was $24 \mathrm{~mm}$, the top left corner of the covering concrete slabs cracked due to the squeeze between the covering concrete slabs and the stiffeners, as shown in Figure 13(a). When the displacement increased to $30 \mathrm{~mm}$, the cracking part of the covering concrete slabs continued to squeeze the stiffeners, which caused the existing cracks to develop further. The top right corner of the covering concrete slabs started to crack for the same reason. When the loading displacement was $38 \mathrm{~mm}$, the squeezing cracks in the top corners became very serious and developed downwards. At the same time, the bottom right corner of the covering concrete slabs started to crack for squeezing. A slanting crack, which ran through the whole covering concrete slabs and extended to the top right corner, appeared as the impact between the infilled steel plate and the covering concrete slabs continued, as shown in Figure 13(b). The final state of destruction is shown in Figure 13(c). It can be observed that a large area of the concrete slab is peeled off.

The final state of the infilled steel plate is shown in Figure 14. It can be observed that the out-of-plane displacement of the infilled steel plate has been restrained effectively by the covering concrete slabs. There are two main tension fields crossing each other along the diagonal lines, which have been developed significantly. There are local bucklings in the four triangular sections which are divided by the two main tension fields. There are twelve cracks on the surface of the infilled steel plate, all of which are located at the junction of the buckling half waves of the steel plate or in the two main tension fields. Obvious frictional imprints caused by the covering concrete slabs and the infilled steel plate can be observed at the positions of the cracks. This is an indication that the energy dissipation performance of the 


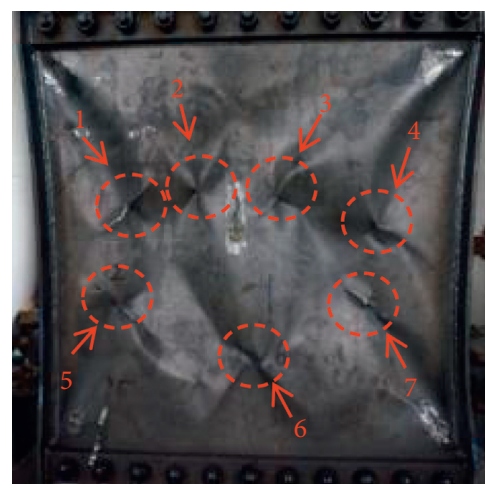

(a)

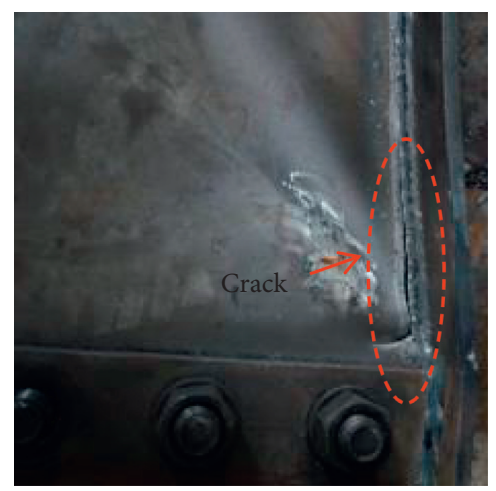

(b)

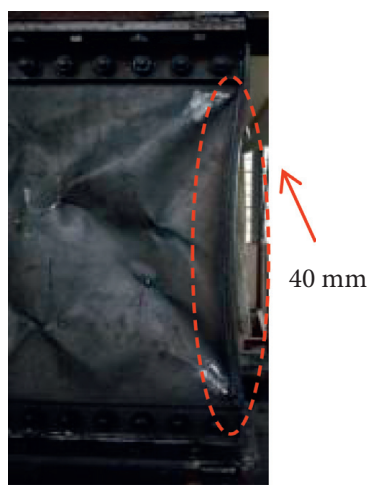

(c)

FIGURE 12: Destruction of SPSW specimen. (a) Cracks on the steel plate surface. (b) Crack in the corner of the steel plate. (c) Inward bending of the steel plate.

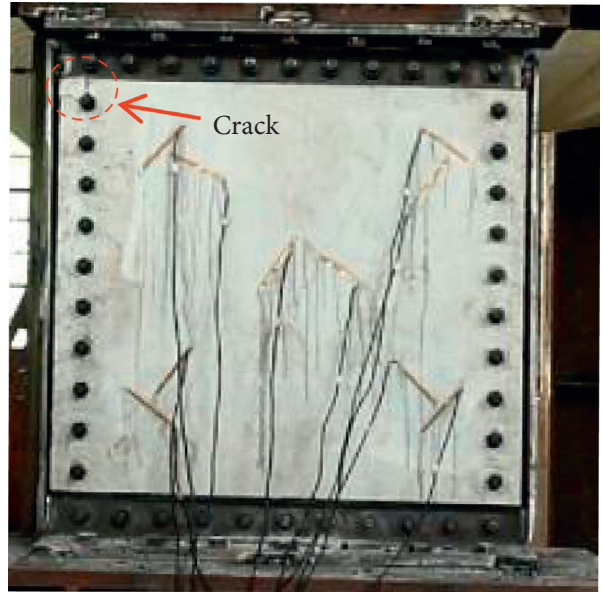

(a)

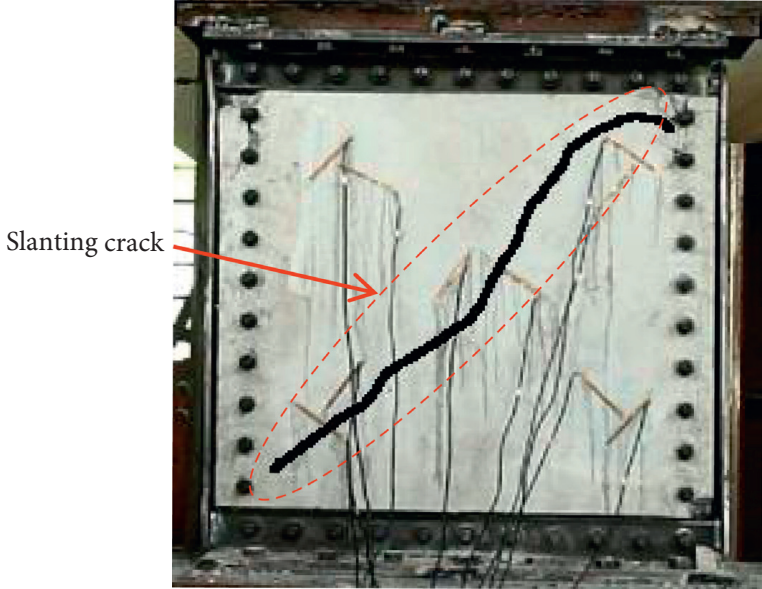

(b)

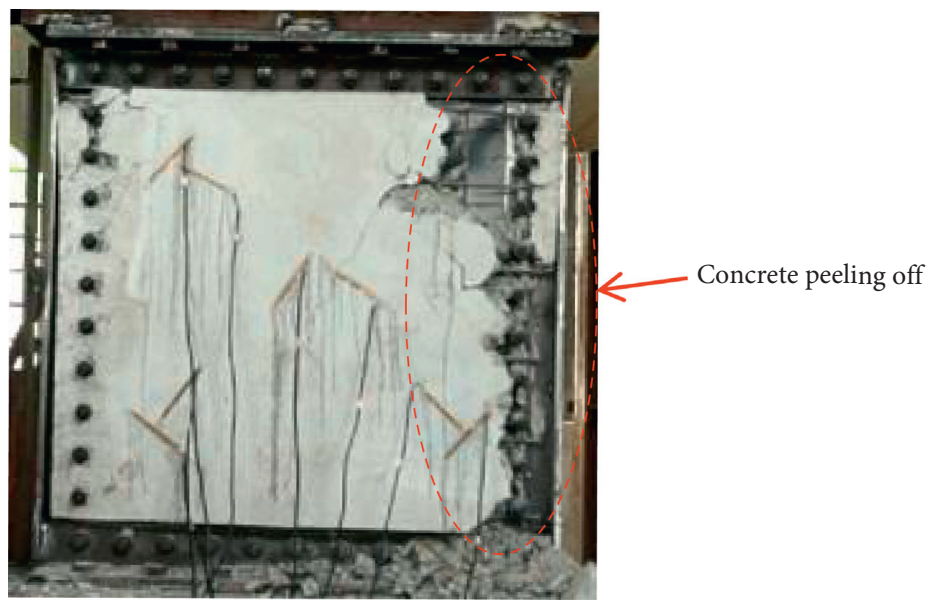

(c)

FIGURE 13: Deformation of BRSPSW specimen under different loading displacements. (a) $24 \mathrm{~mm}$. (b) $38 \mathrm{~mm}$. (c) Final state of destruction.

BRSPSW is better than that of the SPSW. The covering concrete slabs did not only restrain the buckling of the infilled steel plate but also squeezed and rubbed with the infilled steel plate effectively, both of which helped to dissipate the seismic energy. Apart from the cracks on the plate surface, all of the corners of the steel plate did not tear, which is an indication that the destruction of the infilled steel plate was not very serious. Even as the experiment 


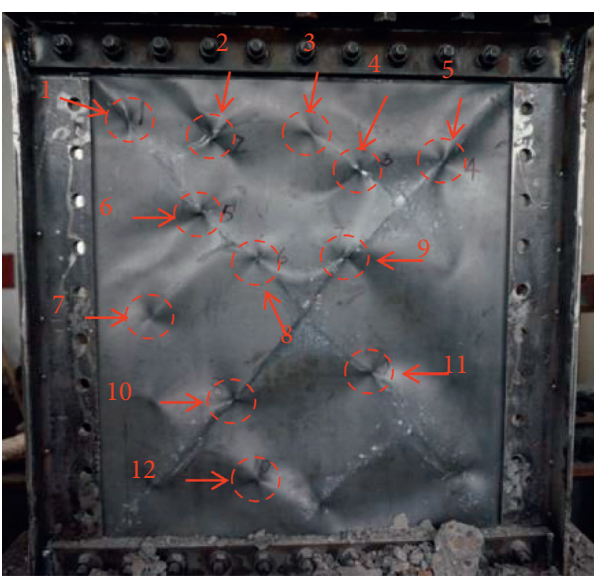

Figure 14: Destruction of infilled steel plate.

continued, the infilled steel plate still continued to carry the loads and dissipate energy, although it was losing the constraint of the covering concrete slabs. Due to the existence of the gaps between the infilled steel plate and the covering concrete slabs, the covering concrete slabs not only bore the squeezes and frictions with the infilled steel plate but also bore the impact by the infilled steel plate when the buckling waves of the infilled steel plate transformed. This increased the burdens on the covering concrete slabs and lessened the burdens on the infilled steel plate. Compared with the SPSW, the positions of the cracks on the surface of the BRSPSW are more symmetrical. The lengths of the twelve cracks are shorter. There are no cracks at the four corners of the infilled steel plate.

\section{Discussions of Test Results}

6.1. Elastic Stiffness and Shear Resistance. Figure 15 shows a comparison of the hysteretic behavior of the two specimens. The hysteretic behavior is characterized by the relationship between the applied lateral forces and lateral displacements. It can be observed that the BRSPSW specimen exhibits good performance in terms of initial stiffness, ultimate strength, ductility, and energy dissipation. The SPSW specimen shows stable cyclic behavior along with obvious pinching that is mainly attributed to the occurrence of buckling in steel plate. The pinching of the BRSPSW specimen has been improved by installing the covering concrete slabs to limit the development of tension fields, but there was still some pinching, which is mainly attributed to the gaps between the infilled steel plate and the covering concrete slabs. Further, the SPSW specimen shows some nonlinear material behavior at the drift ratio level of about $0.44 \%$ ( $4 \mathrm{~mm}$ ) and the BRSPSW specimen shows some nonlinear material behavior at the drift ratio level of about $0.22 \%(2 \mathrm{~mm})$, where the infilled steel plates have yielded in the tension field. At these points, the hysteresis loops are significantly open, and the peak forces are about $259 \mathrm{kN}$ and $228 \mathrm{kN}$, respectively.

A summary of the specimens' response at different cycle level is shown in Table 7. In addition, the initial stiffness, yield point, ultimate load, and maximum displacement of the test specimens are shown in Table 8. Further, the skeleton

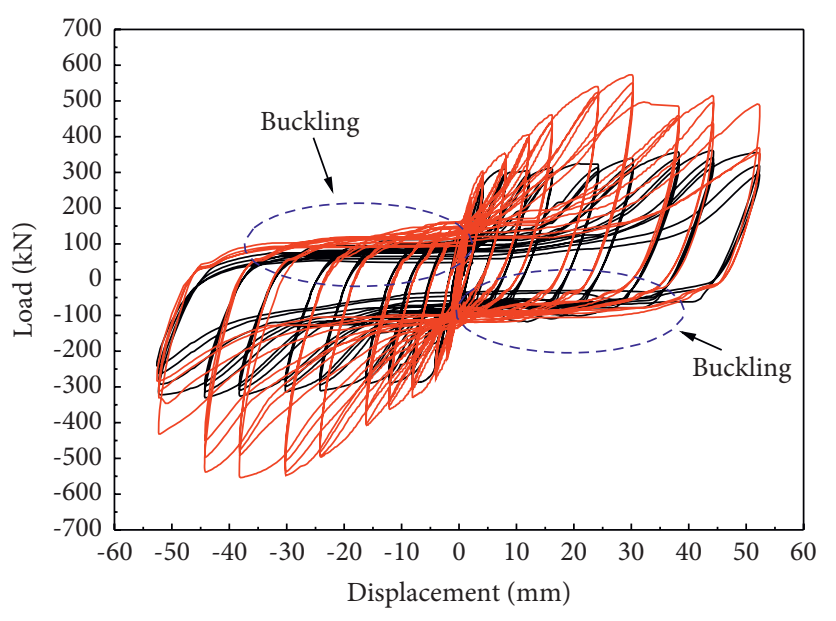

- SPSW

— BRSPSW

FIgURE 15: Hysteretic curves of both specimens.

curves of the loads versus displacements are compared in Figure 16. These curves have been developed by plotting the points with the peak displacement of each cycle level and corresponding applied force. From the curves, it can be observed that the covering concrete slabs have a significant effect on the initial stiffness and the shear resistance of the infilled steel plate. With the constraints of the covering concrete slabs, the initial stiffness of the BRSPSW specimen has increased by 1.6 times higher than that of the SPSW specimen. The maximum resistance of the BRSPSW specimen is approximately 1.6 times higher than that of the SPSW specimen.

Stiffness degradation characteristic can reflect the cumulative damage of structure, which is one of the important characteristics of structural dynamic performance. According to the definition in the Chinese specification for seismic test of buildings (JGJ/T 101-2015 [35]), the equivalent stiffness, $K_{i}$, can be expressed as follows:

$$
K_{i}=\frac{\left|+F_{i}\right|+\left|-F_{i}\right|}{\left|+X_{i}\right|+\left|-X_{i}\right|},
$$

where $+F_{i}$ and $-F_{i}$ are the load values at the $i$-th positive peak point and the $i$-th negative peak point, respectively, and $+X_{i}$ and $-X_{i}$ are the displacement values at the $i$-th positive peak point and the $i$-th negative peak point, respectively. Figure 17 shows a comparison of the equivalent stiffness behavior of the two specimens. The initial stiffness of the BRSPSW specimen is much higher than that of the SPSW specimen, which is mainly attributed to the constraint effect of the covering concrete slabs on both sides of the infilled steel plate of the BRSPSW specimen. The equivalent stiffness of both specimens degenerates gradually with the increase of loading displacement, and the degradation speed of both specimens is fast at the beginning of loading. After the loading displacement exceeds $10 \mathrm{~mm}$, the degradation speed of both specimens slows down and tends to be stable. At the end of the test, the equivalent stiffness of both specimens is 
Table 7: Cyclic test histories.

\begin{tabular}{|c|c|c|c|c|c|c|}
\hline Load procedure & $\begin{array}{c}\text { Load } \\
\text { step }\end{array}$ & $\begin{array}{c}\text { Number of } \\
\text { cycles }\end{array}$ & $\begin{array}{c}\text { Cumulative number of } \\
\text { cycles }\end{array}$ & $\begin{array}{c}\text { Peak load } \\
\left(V_{p}, \mathrm{kN}\right)\end{array}$ & $\begin{array}{c}\text { Displacement } \\
(\Delta, \mathrm{mm})\end{array}$ & $\begin{array}{c}\text { Drift ratio } \\
(\theta, \%)\end{array}$ \\
\hline \multirow{14}{*}{$\begin{array}{l}\text { SPSW } \\
\text { Displacement } \\
\text { controlled }\end{array}$} & & & & & & \\
\hline & 1 & 3 & 3 & 68.94 & 0.57 & 0.06 \\
\hline & 2 & 3 & 6 & 109.87 & 1.04 & 0.11 \\
\hline & 3 & 3 & 9 & 138.43 & 1.40 & 0.15 \\
\hline & 4 & 3 & 12 & 157.02 & 2.05 & 0.22 \\
\hline & 5 & 3 & 15 & 258.74 & 4.14 & 0.45 \\
\hline & 6 & 3 & 18 & 309.64 & 8.03 & 0.87 \\
\hline & 7 & 3 & 21 & 304.88 & 12.01 & 1.31 \\
\hline & 8 & 3 & 24 & 312.75 & 16.08 & 1.75 \\
\hline & 9 & 3 & 27 & 323.19 & 24.03 & 2.61 \\
\hline & 10 & 3 & 30 & 339.40 & 30.11 & 3.27 \\
\hline & 11 & 3 & 33 & 357.80 & 37.99 & 4.13 \\
\hline & 12 & 3 & 36 & 362.10 & 44.14 & 4.80 \\
\hline & 13 & 3 & 39 & 355.42 & 51.92 & 5.64 \\
\hline \multirow{14}{*}{$\begin{array}{l}\text { BRSPSW } \\
\text { Displacement } \\
\text { controlled }\end{array}$} & & & & & & \\
\hline & 1 & 3 & 3 & 106.85 & 0.56 & 0.06 \\
\hline & 2 & 3 & 6 & 156.83 & 1.06 & 0.12 \\
\hline & 3 & 3 & 9 & 194.28 & 1.56 & 0.17 \\
\hline & 4 & 3 & 12 & 227.79 & 2.09 & 0.23 \\
\hline & 5 & 3 & 15 & 303.69 & 4.11 & 0.45 \\
\hline & 6 & 3 & 18 & 353.68 & 7.93 & 0.86 \\
\hline & 7 & 3 & 21 & 405.04 & 12.18 & 1.32 \\
\hline & 8 & 3 & 24 & 460.98 & 16.13 & 1.75 \\
\hline & 9 & 3 & 27 & 540.18 & 24.15 & 2.63 \\
\hline & 10 & 3 & 30 & 573.14 & 30.08 & 3.27 \\
\hline & 11 & 3 & 33 & 497.15 & 32.20 & 3.50 \\
\hline & 12 & 3 & 36 & 514.73 & 44.07 & 4.79 \\
\hline & 13 & 3 & 39 & 491.29 & 51.92 & 5.64 \\
\hline
\end{tabular}

TABle 8: Hysteretic behavior of test specimens.

\begin{tabular}{lcccccc}
\hline Specimen & $\begin{array}{c}\text { Initial stiffness } \\
\left(K_{0}, \mathrm{kN} / \mathrm{mm}\right)\end{array}$ & Yield load $\left(V_{y}, \mathrm{kN}\right)$ & $\begin{array}{c}\text { Yield displacement } \\
\left(\Delta_{y}, \mathrm{~mm}\right)\end{array}$ & $\begin{array}{c}\text { Ultimate load } \\
\left(V_{u}, \mathrm{kN}\right)\end{array}$ & $\begin{array}{c}\text { Maximum displacement } \\
\left(\Delta_{t}, \mathrm{~mm}\right)\end{array}$ & $\begin{array}{c}\text { Ductility ratio } \\
\left(\Delta_{t} / \Delta_{y}\right)\end{array}$ \\
\hline SPSW & 120.95 & 258.75 & 4.14 & 362.10 & 51.92 & 12.54 \\
BRSPSW & 190.80 & 227.79 & 2.09 & 573.14 & 30.08 & 14.39 \\
\hline
\end{tabular}

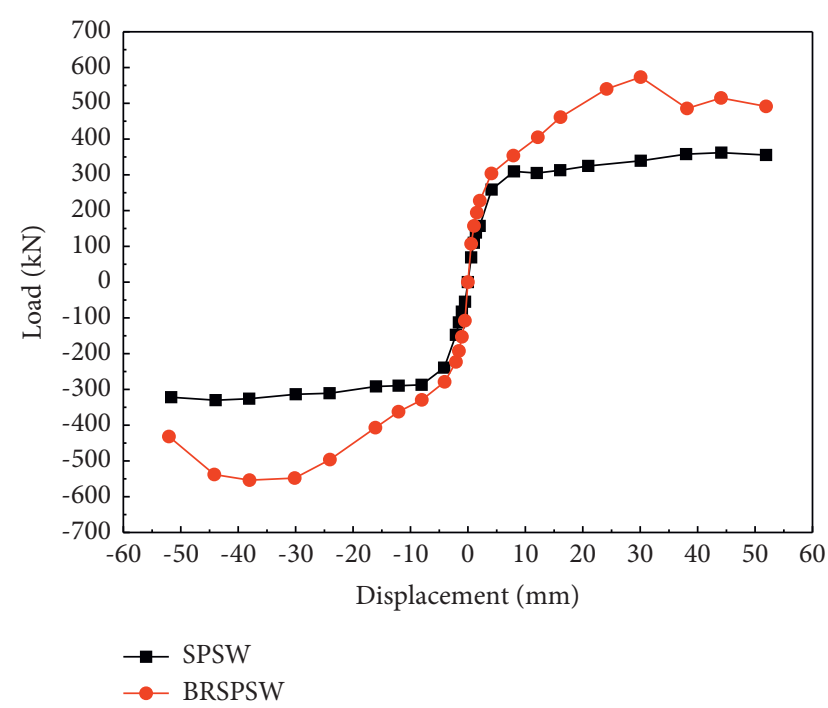

FIGURE 16: Skeleton curves of both specimens.

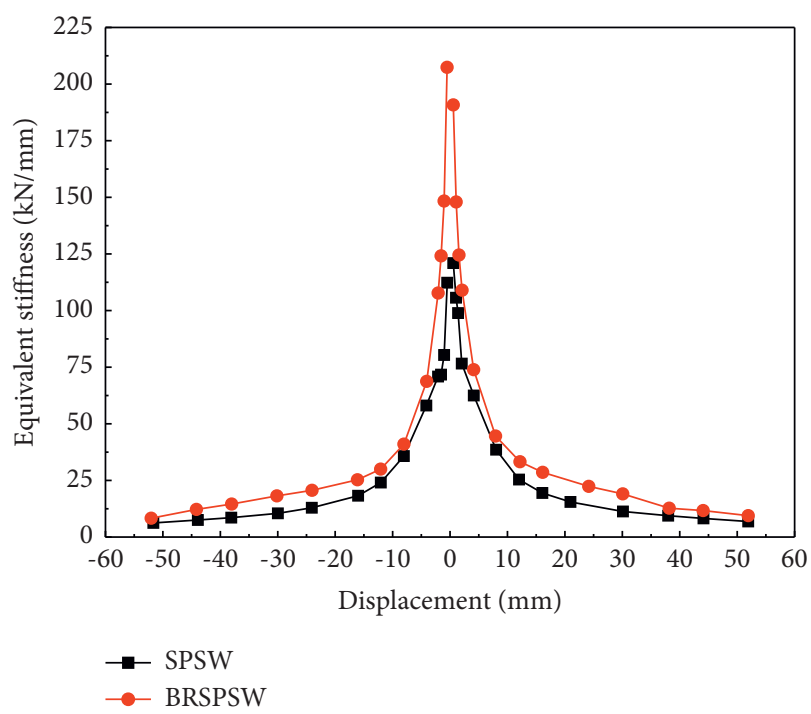

FIgURE 17: Equivalent stiffness curves of both specimens. 
close, about $10 \mathrm{kN} / \mathrm{mm}$. The equivalent stiffness of the BRSPSW specimen is higher than that of the SPSW specimen during the whole loading process.

6.2. Ductility. The test results show that both specimens SPSW and BRSPSW have good ductility. According to the definition in the AISC [39], the ductility factor, $\mu$, can be expressed as follows:

$$
\mu=\frac{\Delta_{t}}{\Delta_{y}}
$$

where $\Delta_{t}$ is the maximum displacement that can be obtained during the tests and $\Delta_{y}$ is the idealized yield displacement. The idealized yield point is defined by the principle of energy conservation, as shown in Figure 18, where the area enclosed by the idealized elastoplastic envelope curve is equal to that enclosed by the actual envelope curve. The ductility factors of the specimens are shown in Table 8 . It can be observed that the ductility factors of both SPSW and BRSPSW specimens have exceeded 12.0, which is an indication of good ductility performance.

6.3. Energy Dissipation Capacity. The amount of energy dissipation is an important factor in seismic design. The cumulative energy dissipations of the two specimens at per cycle level are presented in Figure 18. The energy dissipation is calculated using the average area enclosed by the three complete load-displacement cycle curves at each displacement level. The energy dissipated by the SPSW and BRSPSW specimens is nearly identical for the drift ratio cycle level below $0.22 \%(2 \mathrm{~mm})$. When the drift ratio cycle level becomes higher, the energy dissipation by the BRSPSW specimen exceeds that of the SPSW specimen, and, at the $5.64 \%$ drift ratio cycle level $(52 \mathrm{~mm})$, the energy dissipation by the BRSPSW specimen is greater by a factor of approximately 1.54. In addition, it can be seen from Figure 19 that the energy dissipated by the BRSPSW specimen with the covering concrete slabs is greater than that dissipated by the SPSW specimen.

\section{Numerical Analyses of the Novel BRSPSW}

The novel BRSPSW specimen presented in this paper comes with specific dimensions and parameters which do not cover the full range of cases that might be encountered in practice. It is, therefore, necessary to develop a numerical model to investigate the behavior of the novel BRSPSW with different geometry, avoiding a large expense of conducting additional tests. Thus, a reliable FE model is developed herein to simulate the behavior of the novel BRSPSW subjected to cyclic loading. Meanwhile, the FE model will be validated using the test results, so that it can be used to further analyse the other novel BRSPSW with different configurations.

7.1. Finite Element Model. To simulate the hysteretic characteristics and the strength-deformation characteristics of the novel BRSPSW, the same finite element (FE) model as

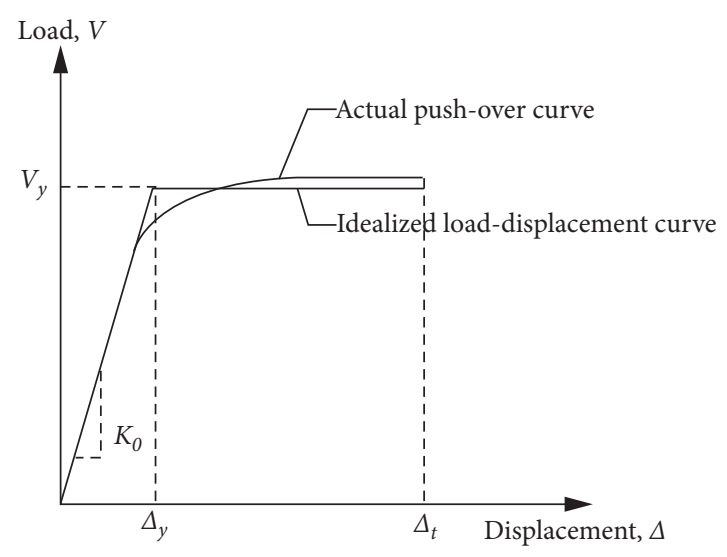

FIgURE 18: General idealized relationship of shear loading versus displacement.

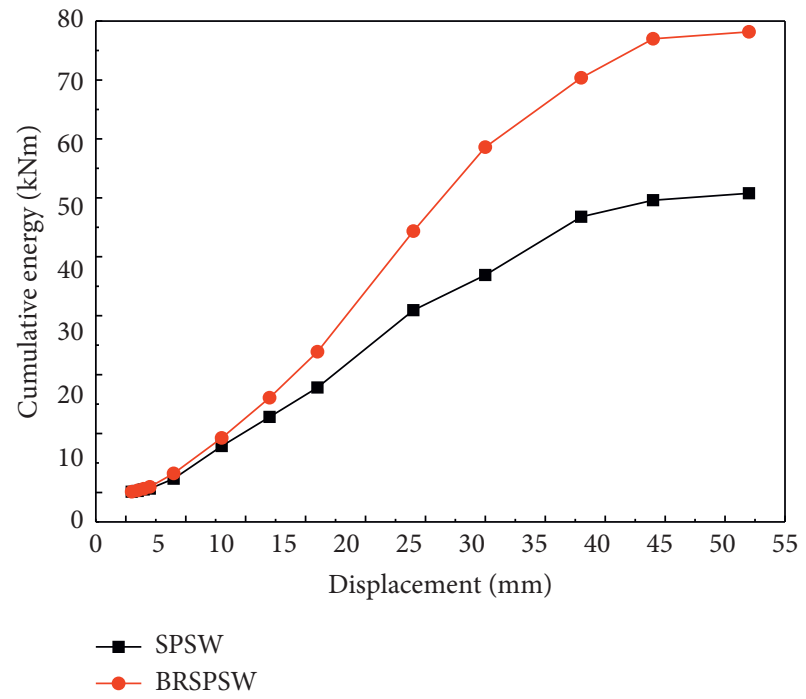

FIgURE 19: Cumulative energy dissipation at each loading step of both specimens.

that in Section 3.1 has been developed using the finite element analysis software ABAQUS/Standard Dynamic to perform hysteretic analysis. The dimensions of each component are exactly the same as those of the test specimen BRSPSW, which can be seen in Table 5. The gap thickness is $10 \mathrm{~mm}$. The angle steel stiffeners are made of Q345 steel with $E_{s}=210 \mathrm{GPa}$ and $f_{y}=354 \mathrm{MPa}$ and the infilled steel plate is made of Q235 steel with $E_{s}=210 \mathrm{GPa}$ and $f_{y}=225 \mathrm{MPa}$, which are the same as those in the material tests results in Table 6. The linear kinematic hardening model was used to simulate the inelastic behavior of steel material, in which $\alpha=0.02$, as shown in Figure 20. Poisson's ratio of the steel material is 0.3 . The concrete damaged plasticity model in ABAQUS has been used to model the concrete material. The covering concrete slabs are made of C30 concrete with $E_{s}=30 \mathrm{GPa}$ and $f_{c}^{\prime}=30 \mathrm{MPa}$, where $f_{c}^{\prime}$ is the cylinder strength of concrete. Poisson's ratio of concrete material is 0.2 . The plastic coefficients of the concrete material adopt the same values in Table 2. Regarding the initial geometric imperfection of the infilled steel plate, it is recommended in 


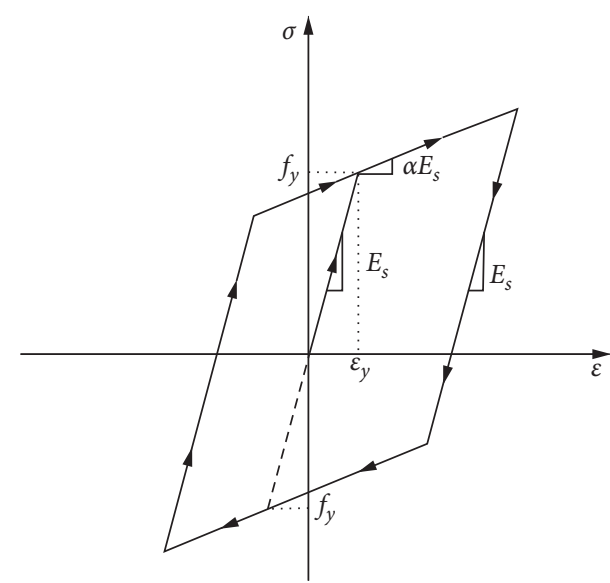

FIgURE 20: Stress-strain relationship of steel.

GB50205-2001 [34] that it should be not greater than 1\%o$1.5 \%$ of the storey height. Herein an initial geometric imperfection of $1.0 \mathrm{~mm}$ is adopted.

7.2. Validation of FE Model against Test Results. The elastic buckling analysis has been carried out first on the infilled steel plate without covering the concrete slabs in order to acquire the imperfection shape. Then, the horizontal low cyclic loading, which is the same as that in the test loading procedure, is applied to the novel BRSPSW finite element (FE) model, as shown in Figure 10. The test results of the novel BRSPSW described in Section 6.1 are used to verify the proposed FE model. Figure 21 shows the comparison between the finite element results and the test results of the novel BRSPSW under horizontal low cyclic loading. In the comparison of hysteretic curves, the finite element results can reflect the hysteretic characteristics of the novel BRSPSW in a certain extent, as shown in Figure 21(a). In the comparison of skeleton curves, the finite element results can reflect the strength-deformation characteristics of the novel BRSPSW well, as shown in Figure 21(b). However, the hysteretic curve of the finite element results is fuller than that of the test results, and the initial stiffness and bearing capacity of the finite element results are higher than those of the test results, which are all mainly attributed to the slipping between the infilled steel plate and the fish plate and that between the bolts and the bolt holes in test. Overall, it can be observed that the proposed FE model can reasonably predict the shear resistance, overall hysteretic responses, and skeleton curve of the test specimen. Thus, based on the validated FE model, an extensive parametric study can be performed to investigate the seismic behavior of the novel BRSPSW.

7.3. Parametric Studies on the Novel BRSPSW. The validated FE model is employed to conduct the nonlinear analysis of the novel BRSPSW with various geometric conditions. A total of $22 \mathrm{FE}$ models is built having different slenderness ratio (height/thickness) and aspect ratio (width/height) of infilled steel plate, concrete slab thickness, and gap thickness between the infilled steel plate and the covering concrete slabs. The lateral cyclic loading is adopted in FE models and each level of load is cycled only once to improve computational efficiency. The amplitudes of the enforced horizontal displacement are $0.5 \mathrm{~mm}, 1 \mathrm{~mm}, 1.5 \mathrm{~mm}, 2 \mathrm{~mm}, 4 \mathrm{~mm}$, $6 \mathrm{~mm}, 8 \mathrm{~mm}, 12 \mathrm{~mm}, 16 \mathrm{~mm}$, and $20 \mathrm{~mm}$.

7.3.1. Effect of Slenderness Ratio of Infilled Steel Plate. To evaluate the effect of the slenderness ratio of infilled steel plate on the shear resistance and hysteretic behavior of the novel BRSPSW, four FE models with various slenderness ratio, $\lambda$, namely, $150,200,300$, and 600 , are built in this section, where the height of the infilled steel plate is kept constant as $900 \mathrm{~mm}$ and the corresponding thickness is $6 \mathrm{~mm}, 4.5 \mathrm{~mm}, 3 \mathrm{~mm}$, and $1.5 \mathrm{~mm}$, respectively. The geometric and material properties of FE models are listed in Table 9. Because of the different amounts of steel used for infilled steel plates in FE models with different slenderness ratios, it is difficult to compare the seismic behavior of the novel BRSPSW under different slenderness ratios directly. Therefore, the shear load is given in the form of average shear stress, $\tau$, to describe the shear resistance and hysteretic behavior of the novel BRSPSW, which can be expressed as follows:

$$
\tau=\frac{V}{T \times L},
$$

where $V$ is shear load, $T$ is the thickness of infilled steel plate, and $L$ is the width of infilled steel plate. It can be seen from Figure 22 that the slenderness ratio of infilled steel plate has a great effect on the shear resistance and hysteretic behavior of the novel BRSPSW. Because of the increase of infilled steel plate's thickness with the decrease of the slenderness ratio, the hysteretic curves of the novel BRSPSW become fuller and fuller, and the ultimate average shear stress increases gradually. The ultimate average shear stress of the FE model with the slenderness ratio of 150 is about $160 \mathrm{MPa}$. Up to the slenderness ratio of 600 , the ultimate average shear stress dramatically drops to $117 \mathrm{MPa}$ and approximately $73 \%$ of the former.

7.3.2. Effect of Aspect Ratio of Infilled Steel Plate. To evaluate the effect of the aspect ratio of infilled steel plate on the shear resistance and hysteretic behavior of the novel BRSPSW, four FE models with various aspect ratios, namely, 0.5, 1.0, 1.5 , and 2.0, are built in this section, where the height of the infilled steel plate is kept constant as $900 \mathrm{~mm}$ and the corresponding width is $450 \mathrm{~mm}, 900 \mathrm{~mm}, 1350 \mathrm{~mm}$, and $1800 \mathrm{~mm}$, respectively. The geometric and material properties of FE models are listed in Table 10. Because of the different amounts of steel used for infilled steel plates in FE models with different aspect ratios, the shear load is also given in the form of average shear stress, $\tau$, which can be calculated by equation (3). It can be seen from Figure 23 that the aspect ratio of infilled steel plate has a great effect on hysteretic behavior but a little effect on shear resistance of the novel BRSPSW. With the decrease of the aspect ratio of infilled steel plate, the bending deformation component has a more significant effect on the seismic behavior of the novel 


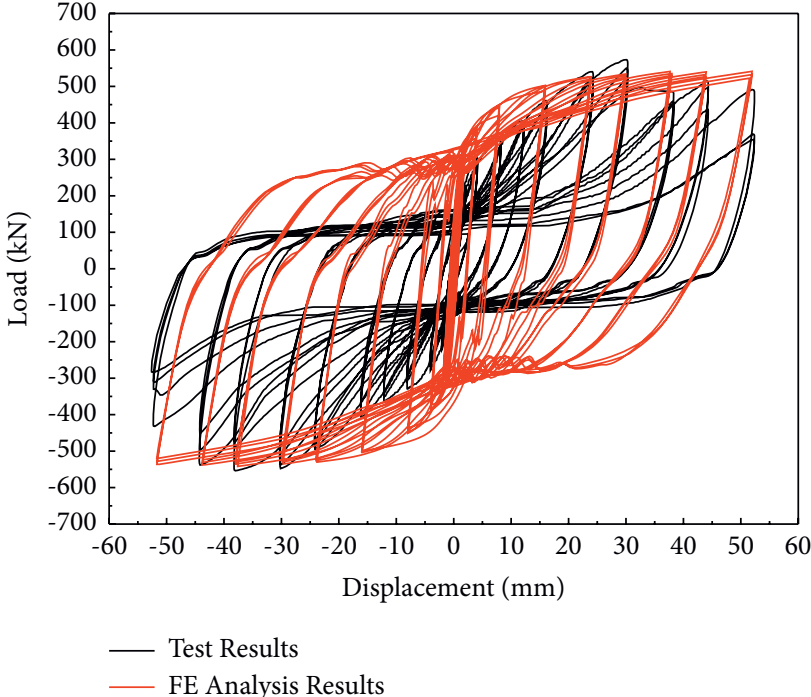

(a)

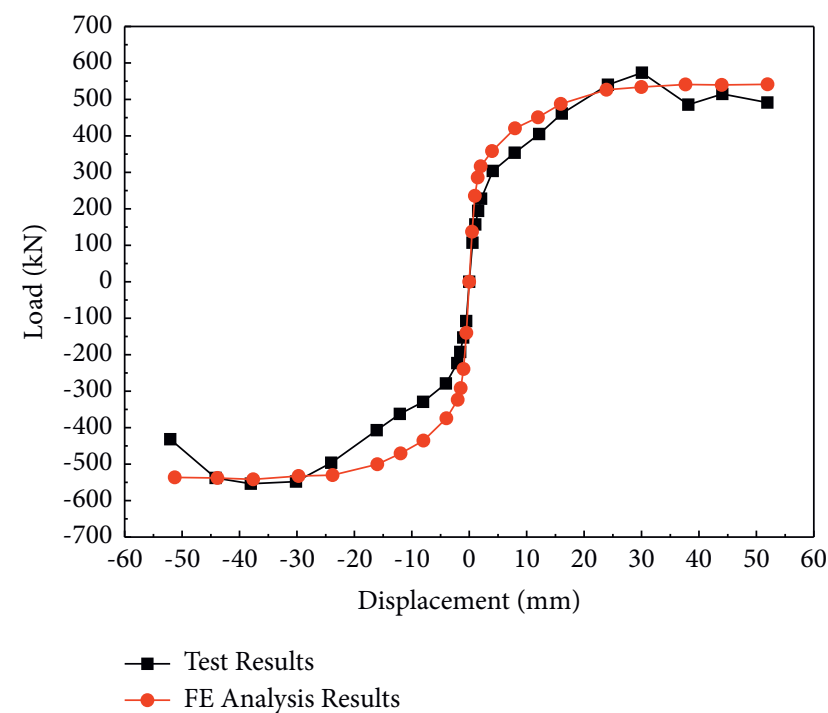

(b)

Figure 21: Comparison between test results and FE analysis results. (a) Hysteretic curves. (b) Skeleton curves.

TABle 9: Details of FE models (slenderness ratio).

\begin{tabular}{lccccccc}
\hline \multicolumn{9}{c}{ Infilled steel plate } & & & & \\
FE model & Width & Height & Thickness & Slenderness ratio $(\lambda=H / T)$ & Aspect ratio $(L / H)$ & $\begin{array}{c}\text { Concrete slab } \\
\text { thickness }(\mathrm{mm})\end{array}$ & Gap thickness $(\mathrm{mm})$ \\
\hline Model 1-1 & 900 & 900 & 6 & 150 & 1.0 & 45 & 10 \\
Model 1-2 & 900 & 900 & 4.5 & 200 & 1.0 & 45 & 10 \\
Model 1-3 & 900 & 900 & 3 & 300 & 1.0 & 45 & 10 \\
Model 1-4 & 900 & 900 & 1.5 & 600 & 1.0 & 45 & 10 \\
\hline
\end{tabular}

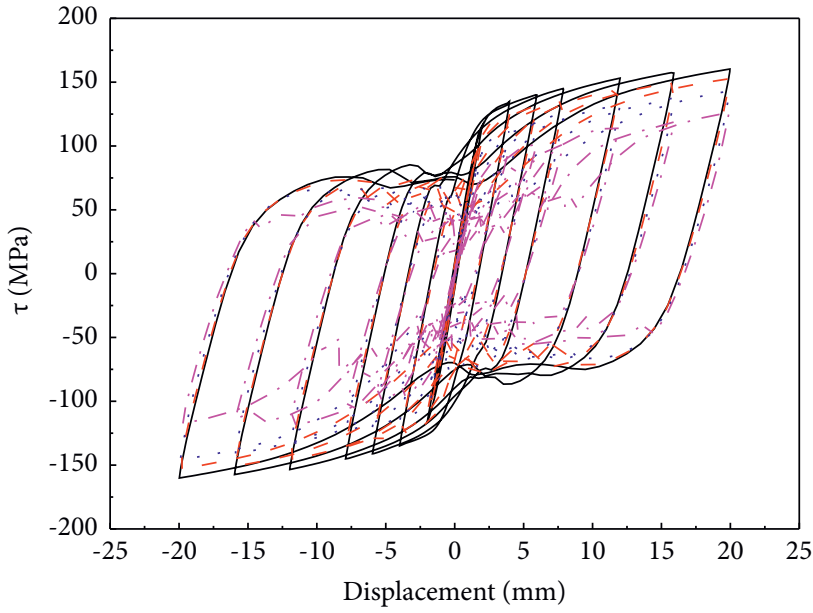

$\begin{aligned} \lambda & =150 \\ --\lambda & =200\end{aligned}$

$$
\begin{aligned}
& \cdots . \lambda=300 \\
& \cdots-\lambda=600
\end{aligned}
$$

(a)

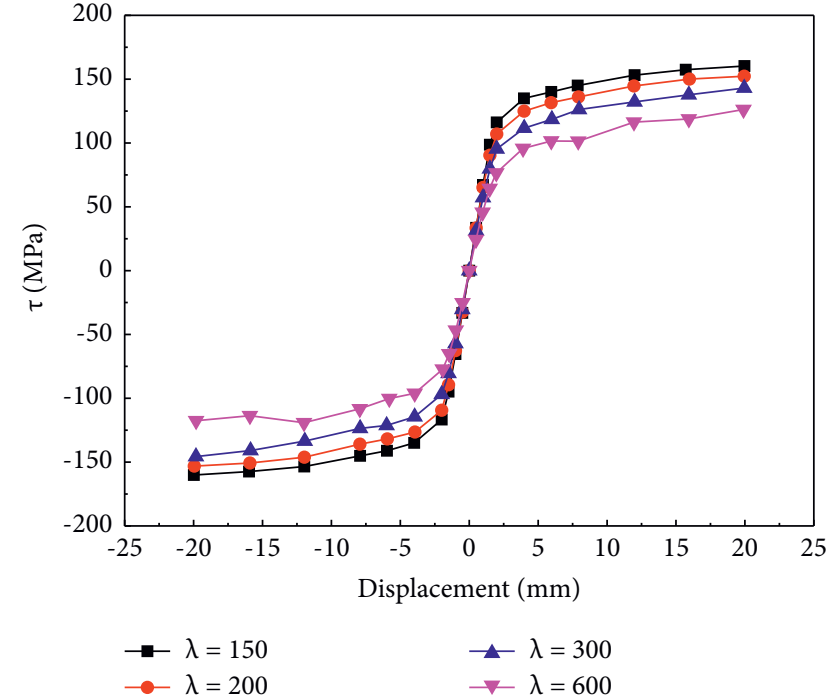

(b)

Figure 22: The effect of slenderness ratio. (a) Hysteretic curves. (b) Skeleton curves. 
TABLE 10: Details of FE models (aspect ratio).

\begin{tabular}{lccccccc}
\hline \multicolumn{9}{c}{ Infilled steel plate } & & & \multicolumn{2}{c}{ Concrete slab } \\
FE model & Width & Height & Thickness & Slenderness ratio $(\lambda=H / T)$ & Aspect ratio $(L / H)$ & $\begin{array}{c}\text { Gap thickness }(\mathrm{mm}) \\
\text { thickness }(\mathrm{mm})\end{array}$ \\
\hline Model 2-1 & 450 & 900 & 3 & 300 & 0.5 & 45 & 10 \\
Model 2-2 & 900 & 900 & 3 & 300 & 1.0 & 45 & 10 \\
Model 2-3 & 1350 & 900 & 3 & 300 & 1.5 & 45 & 10 \\
Model 2-4 & 1800 & 900 & 3 & 300 & 2.0 & 45 & 10 \\
\hline
\end{tabular}

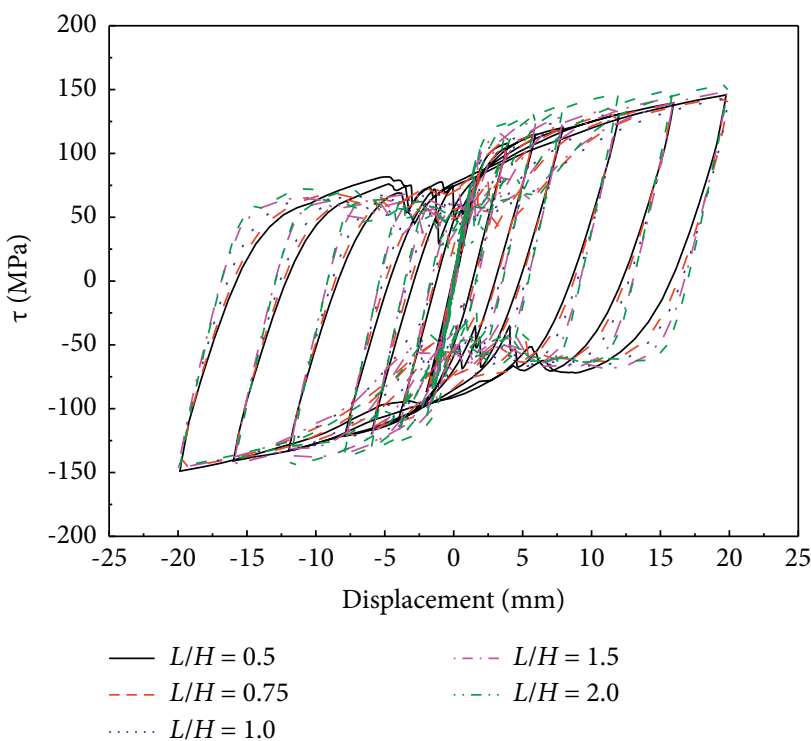

(a)

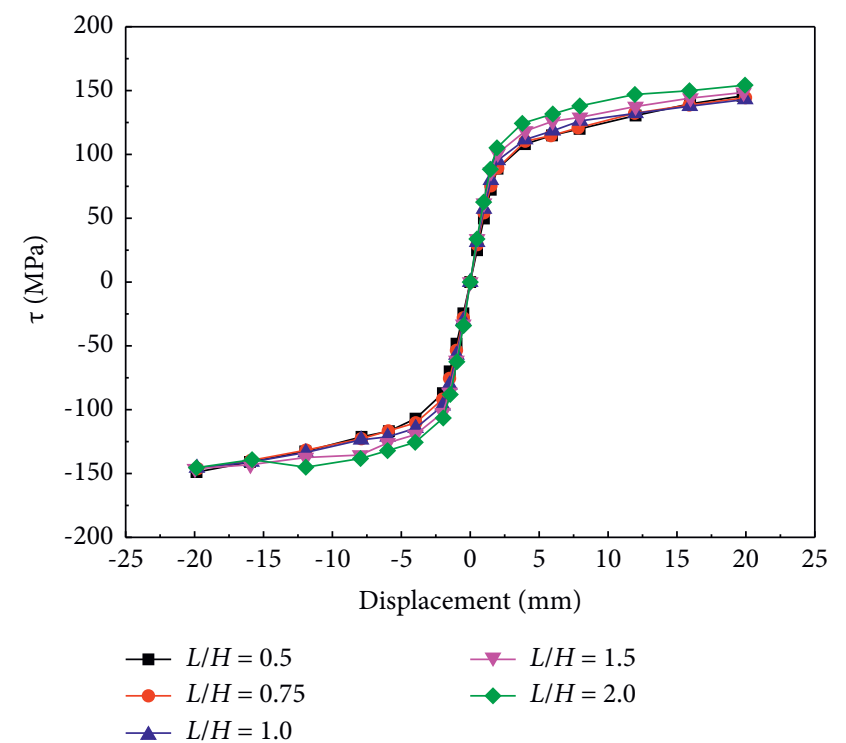

(b)

Figure 23: The effect of aspect ratio. (a) Hysteretic curves. (b) Skeleton curves.

BRSPSW. Therefore, the hysteretic curve of the FE model with the aspect ratio of 0.5 is the fullest. The ultimate average shear stress of the FE model with the aspect ratio of 0.5 is about $146 \mathrm{MPa}$. Up to the aspect ratio of 2.0 , the ultimate average shear stress dramatically drops to $154 \mathrm{MPa}$ and approximately $105 \%$ of the former.

7.3.3. Effect of Concrete Slab Thickness. The concrete slabs can effectively restrain the buckling of infilled steel plate depending on whether it can provide sufficient out-of-plane stiffness. The concrete slab thickness directly affects its outof-plane stiffness. To evaluate the effect of the concrete slab thickness on the shear resistance and hysteretic behavior of the novel BRSPSW, six FE models with various concrete slab thickness, namely, $15 \mathrm{~mm}, 30 \mathrm{~mm}, 45 \mathrm{~mm}, 60 \mathrm{~mm}, 75 \mathrm{~mm}$, and $90 \mathrm{~mm}$, are built in this section, where the height and the width of the infilled steel plate are kept constant as $900 \mathrm{~mm}$ and $900 \mathrm{~mm}$, respectively. The geometric and material properties of FE models are listed in Table 11. It can be seen from Figure 24 that an increase in shear resistance is apparently observed and the hysteretic curves become fuller gradually as the concrete slab thickness is varied from $15 \mathrm{~mm}$ to $75 \mathrm{~mm}$. After the concrete slab thickness of $75 \mathrm{~mm}$ is reached, the ultimate bearing capacity of the novel BRSPSW will hardly increase. It indicates that, after a certain value of the concrete slab thickness is reached, the concrete slab can provide sufficient out-of-plane stiffness to avoid the buckling of infilled steel plate.

7.3.4. Effect of Gap Thickness. Compared with the traditional buckling-restrained steel plate shear walls clamped by infilled steel plate and concrete slabs through bolts, the gap thickness between the infilled steel plate and the covering concrete slabs has a great effect on the seismic behavior of the novel BRSPSW. To evaluate the effect of the gap thickness on the shear resistance and hysteretic behavior of the novel BRSPSW, eight FE models with various gap thickness, namely, $5 \mathrm{~mm}, 7.5 \mathrm{~mm}, 10 \mathrm{~mm}, 12.5 \mathrm{~mm}, 15 \mathrm{~mm}$, $17.5 \mathrm{~mm}, 20 \mathrm{~mm}$, and $30 \mathrm{~mm}$, are built in this section, where the height and the width of the infilled steel plate are kept constant as $900 \mathrm{~mm}$ and $900 \mathrm{~mm}$, respectively. The geometric and material properties of FE models are listed in Table 12. It can be seen from Figure 25 that, with the increase of the gap thickness, the restrained effect of the concrete slabs on the infilled steel plate decreases, resulting in an obvious drop of the ultimate bearing capacity of the novel BRSPSW. The ultimate bearing capacity of the FE model with the gap thickness of $5 \mathrm{~mm}$ is about $400 \mathrm{kN}$. Up to the 
TABLE 11: Details of FE models (concrete slab thickness).

\begin{tabular}{|c|c|c|c|c|c|c|c|}
\hline \multirow[b]{2}{*}{ FE model } & \multicolumn{3}{|c|}{ Infilled steel plate } & \multirow[b]{2}{*}{ Slenderness ratio $(\lambda=H / T)$} & \multirow[b]{2}{*}{ Aspect ratio $(L / H)$} & \multirow{2}{*}{$\begin{array}{l}\text { Concrete slab } \\
\text { thickness }(\mathrm{mm})\end{array}$} & \multirow[b]{2}{*}{ Gap thickness (mm) } \\
\hline & $\begin{array}{l}\text { Width } \\
(L, \mathrm{~mm})\end{array}$ & $\begin{array}{l}\text { Height } \\
(H, \mathrm{~mm})\end{array}$ & $\begin{array}{l}\text { Thickness } \\
(T, \mathrm{~mm})\end{array}$ & & & & \\
\hline Model 3-1 & 900 & 900 & 3 & 300 & 1.0 & 15 & 10 \\
\hline Model 3-2 & 900 & 900 & 3 & 300 & 1.0 & 30 & 10 \\
\hline Model 3-3 & 900 & 900 & 3 & 300 & 1.0 & 45 & 10 \\
\hline Model 3-4 & 900 & 900 & 3 & 300 & 1.0 & 60 & 10 \\
\hline Model 3-5 & 900 & 900 & 3 & 300 & 1.0 & 75 & 10 \\
\hline Model 3-6 & 900 & 900 & 3 & 300 & 1.0 & 90 & 10 \\
\hline
\end{tabular}

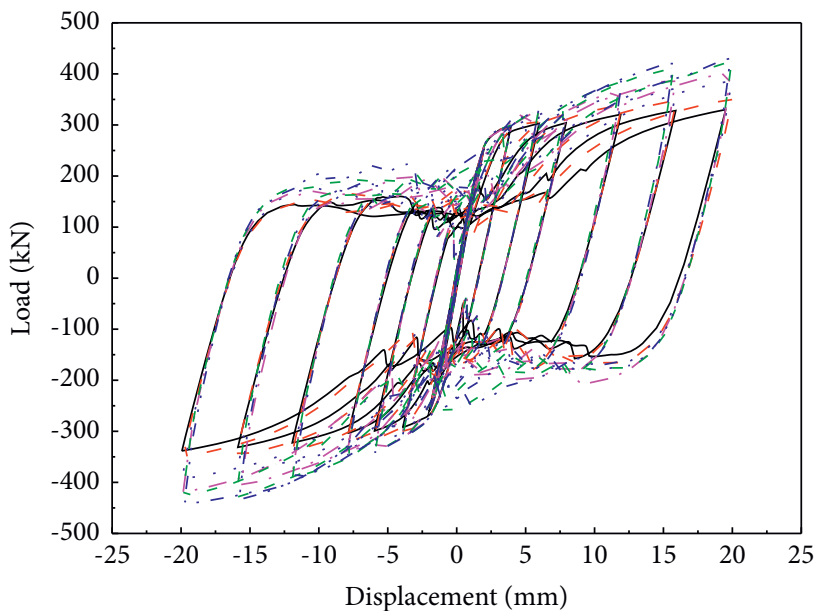

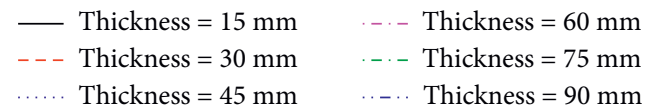

(a)

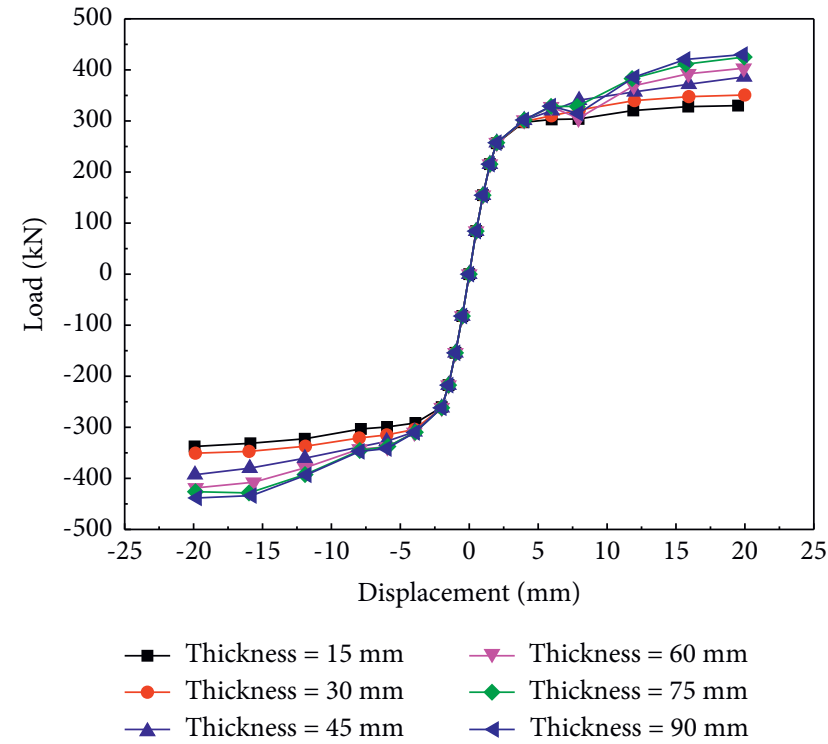

(b)

Figure 24: The effect of concrete slab thickness. (a) Hysteretic curves. (b) Skeleton curves.

TABle 12: Details of FE models (gap thickness).

\begin{tabular}{|c|c|c|c|c|c|c|c|}
\hline \multirow[b]{2}{*}{ FE model } & \multicolumn{3}{|c|}{ Infilled steel plate } & \multirow[b]{2}{*}{ Slenderness ratio $(\lambda=H / T)$} & \multirow[b]{2}{*}{ Aspect ratio $(L / H)$} & \multirow{2}{*}{$\begin{array}{l}\text { Concrete slab } \\
\text { thickness }(\mathrm{mm})\end{array}$} & \multirow[b]{2}{*}{ Gap thickness $(\mathrm{mm})$} \\
\hline & $\begin{array}{l}\text { Width } \\
(L, \mathrm{~mm})\end{array}$ & $\begin{array}{l}\text { Height } \\
(H, \mathrm{~mm})\end{array}$ & $\begin{array}{l}\text { Thickness } \\
(T, \mathrm{~mm})\end{array}$ & & & & \\
\hline Model 4-1 & 900 & 900 & 3 & 300 & 1.0 & 45 & 5 \\
\hline Model 4-2 & 900 & 900 & 3 & 300 & 1.0 & 45 & 7.5 \\
\hline Model 4-3 & 900 & 900 & 3 & 300 & 1.0 & 45 & 10 \\
\hline Model 4-4 & 900 & 900 & 3 & 300 & 1.0 & 45 & 12.5 \\
\hline Model 4-5 & 900 & 900 & 3 & 300 & 1.0 & 45 & 15 \\
\hline Model 4-6 & 900 & 900 & 3 & 300 & 1.0 & 45 & 17.5 \\
\hline Model 4-7 & 900 & 900 & 3 & 300 & 1.0 & 45 & 20 \\
\hline Model 4-8 & 900 & 900 & 3 & 300 & 1.0 & 45 & 30 \\
\hline
\end{tabular}




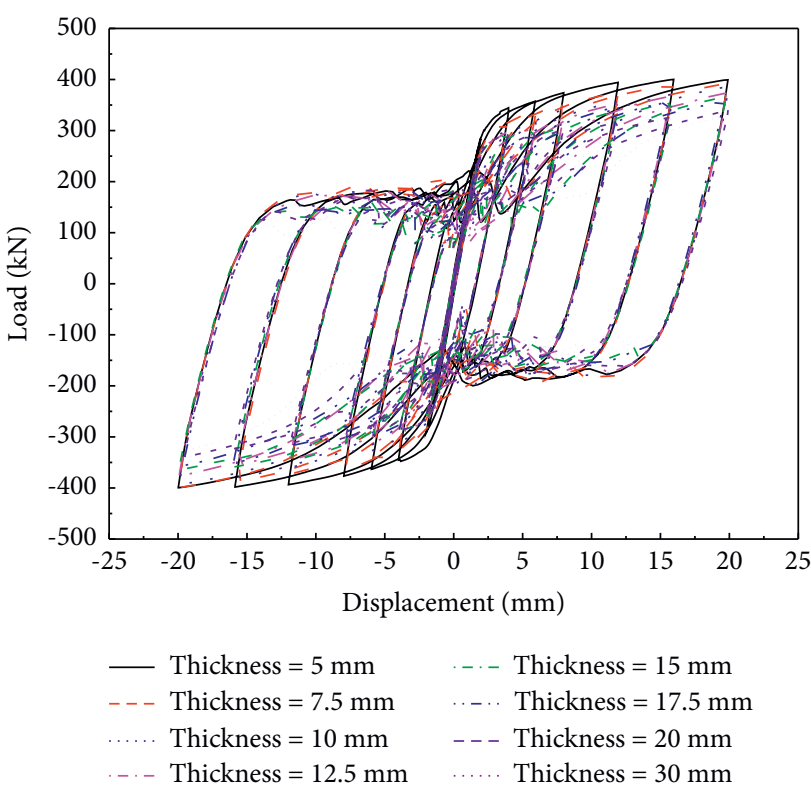

(a)

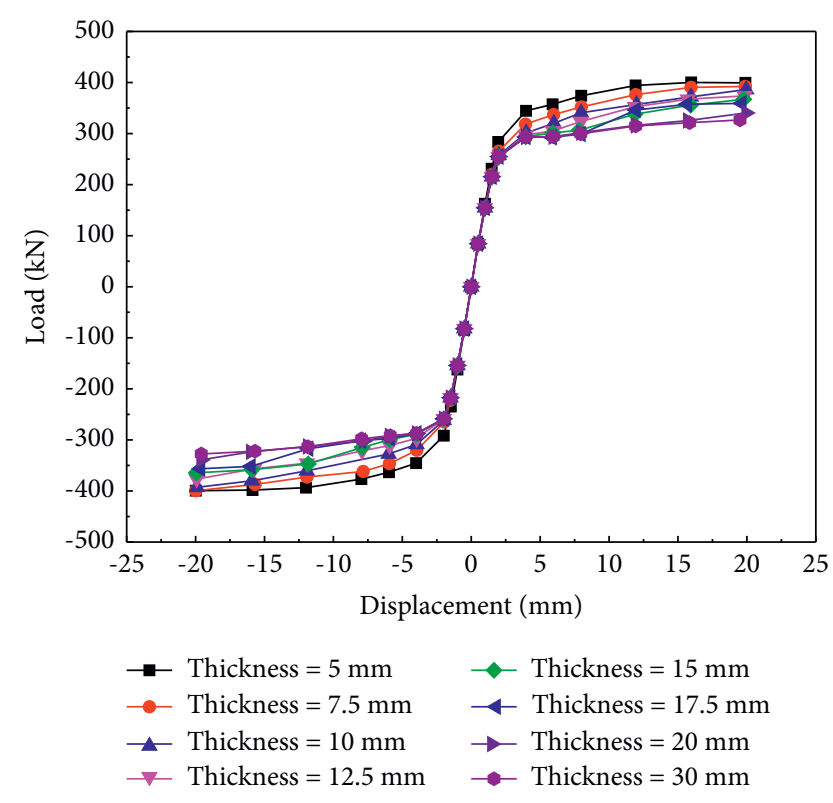

(b)

Figure 25: The effect of gap thickness. (a) Hysteretic curves. (b) Skeleton curves.

gap thickness of $30 \mathrm{~mm}$, the ultimate bearing capacity drops to $326 \mathrm{kN}$ and approximately $81.5 \%$ of the former.

\section{Conclusions}

In this study, a novel energy dissipation device, the BRSPSW, has been proposed as a lateral load-resisting system in highrise structures to dissipate energy due to earthquake in retrofitted or newly constructed structures. Two scaled test specimens have been fabricated and tested. Furthermore, an extensive parametric study is also conducted to investigate the effect of the slenderness ratio and aspect ratio of infilled steel plate, concrete slab thickness, and gap thickness between the infilled steel plate and the covering concrete slabs on seismic behavior of the novel BRSPSW. Based on the investigations, the following conclusions can be drawn:

(1) As a lateral load-resisting system in high-rise structures, the BRSPSW can bear the load once the interstory displacement occurs. The BRSPSW will yield and begin to dissipate energy when the interstory drift ratio is $0.22 \%$, which is earlier than that of the buckling of the infilled steel plate and makes the BRSPSW a good energy dissipation device. At the same time, the infilled steel plate of the BRSPSW is only connected with the surrounding frame beams. There will be no additional bending moment produced to the frame columns. Therefore, the premature failure of the frame columns can be avoided to ensure the structural safety. At the same time, the layout of the BRSPSW is flexible in structures.

(2) At the initial stage of test loading, the SPSW's hysteretic curve was inverted $S$ shape with poor energy dissipation capacity, but the BRSPSW's was shuttle shape with good energy dissipation capacity.
However, with the increase of loading displacement, the BRSPSW's hysteretic curve was gradually transformed into bow shape and finally into inverted $S$ shape. The hysteresis performance of the BRSPSW has been improved to a certain extent. Due to the gaps between the infilled steel plate and the covering concrete slabs, it is difficult to completely limit the out-of-plane buckling of the infilled steel plate, resulting in obvious pinch effect of hysteresis curve.

(3) With the constraints of the covering concrete slabs, the initial stiffness of the BRSPSW has increased by 1.6 times higher than that of the SPSW. The maximum resistance of the BRSPSW is approximately 1.6 times higher than that of the SPSW. The energy dissipation by the BRSPSW exceeds that of the SPSW by a factor of approximately 1.54 at the $5.64 \% \mathrm{drift}$ ratio cycle level $(52 \mathrm{~mm})$.

(4) The novel BRSPSW deferred the destruction of the infilled steel plate. The infilled steel plate maintained basic integrity at the end of test and there were no cracks at the four corners of the infilled steel plate, which is an indication that the infilled steel plate still had the capacity of carrying loads and dissipating energy.

(5) The covering concrete slabs not only bear the squeezes and frictions with the infilled steel plate but also bear the impact by the infilled steel plate when the buckling waves of the infilled steel plate transformed, which accelerated its destruction. So the covering concrete slabs should meet a higher requirement.

(6) The gap between the infilled steel plate and the covering concrete slab forms an out-of-plane 
deformation space of the infilled steel plate. This can ease the stress concentration of the four corners of the infilled steel plate and significantly change the mechanical form of the novel BRSPSW.

(7) The test results show that the novel BRSPSW has high initial stiffness, adequate ductility, excellent energy absorption capacity, and stable hysteresis loop. Therefore, the proposed BRSPSW system is an effective solution to dissipate energy due to the reversal wind or earthquake loads.

(8) The parametric studies conducted using the nonlinear finite element analysis method show that the slenderness ratio and aspect ratio of infilled steel plate, concrete slab thickness, and gap thickness between the infilled steel plate and the covering concrete slabs can have significant effect on the seismic performance of the novel BRSPSW. The shear resistance and hysteretic behavior are greatly improved with the decrease of the slenderness ratio and the gap thickness, as well as the increase of the concrete slab thickness. However, after a certain value of the concrete slab thickness is reached, the ultimate bearing capacity of the novel BRSPSW will hardly increase. In addition, the aspect ratio has a great effect on hysteretic behavior but a little effect on shear resistance of the novel BRSPSW. With the decrease of the aspect ratio, the hysteretic curve of the FE model becomes fuller.

\section{Data Availability}

The data used to support the findings of this study are available from the corresponding author upon request.

\section{Conflicts of Interest}

The authors declare that there are no conflicts of interest regarding the publication of this paper.

\section{Acknowledgments}

This work was financially supported by National Key R\&D Program of China under Grant no. 2017YFC0703600, the National Natural Science Foundation under Grant no. 51978185, Key R\&D and Promotion Projects in Henan Province under Grant no. 192102310520, and Key Scientific Research Projects of Colleges and Universities in Henan Province under Grant no. 20A560016.

\section{References}

[1] L. J. Thorburn, G. L. Kulak, and C. J. Montgomery, Analysis of Steel Plate Shear walls, Structural Engineering Report, no. 107, Department of Civil Engineering, University of Alberta, Edmonton, Canada, 1983.

[2] A. Astaneh-Asl, Seismic Behavior and Design of Steel Shear walls-SEONC Seminar, Structural Engineers Associate of Northern California, San Francisco, CA, USA, 2001.

[3] Y. Lv, L. Li, D. Wu, B. Zhong, Y. Chen, and N. chouw, "Experimental investigation of steel plate shear walls under shear-compression interaction," Shock and Vibration, vol. 2019, Article ID 8202780, 11 pages, 2019.

[4] M. Elgaaly, V. Caccese, and C. Du, "Post-buckling behavior of steel-plate shear walls under cyclic loads," Journal of Structural Engineering, ASCE, vol. 2, no. 119, pp. 588-605, 1993.

[5] V. Caccese, M. Elgaaly, and R. Chen, "Experimental study of thin steel-plate shear walls under cyclic load," Journal of Structural Engineering, ASCE, vol. 119, no. 2, pp. 573-588, 1991.

[6] M. A. Sigariyazd, A. Joghataie, and N. K. A. Attari, "Analysis and design recommendations for diagonally stiffened steel plate shear walls," Thin-Walled Structures, vol. 103, pp. 72-80, 2016.

[7] J.-G. Yu, X.-T. Feng, B. Li, and J.-P. Hao, "Cyclic performance of cross restrained steel plate shear walls with transverse braces," Thin-Walled Structures, vol. 132, pp. 250-264, 2018.

[8] Z. G. Cao, Z. C. Wang, P. Du et al., "Research on steel plate shear walls stiffened with $\mathrm{X}$-shaped restrainers: hysteretic behavior and effect of height-to-thickness ratio of steel plate," Thin-Walled Structures, vol. 144, Article ID 106316, 2019.

[9] W. Wang, J. H. Kong, Y. F. Zhang, and G. Chu, "Seismic behavior of self-centering modular panel with slit steel plate shear walls: experimental testing," Journal of Structural Engineering, ASCE, vol. 144, no. 1, Article ID 04017179, 2018.

[10] J. Lu, S. Yu, J. Xia, X. Qiao, and Y. Tang, "Experimental study on the hysteretic behavior of steel plate shear wall with unequal length slits," Journal of Constructional Steel Research, vol. 147, pp. 477-487, 2018.

[11] J. Y. Lu, L. N. Yan, Y. Tang, and H. Wang, "Study on seismic performance of a stiffened steel plate shear wall with slits," Shock and Vibration, vol. 2015, Article ID 689373, 16 pages, 2015.

[12] Z.-y. Ma, J.-p. Hao, and H.-s. Yu, "Shaking-table test of a novel buckling-restrained multi-stiffened low-yield-point steel plate shear wall," Journal of Constructional Steel Research, vol. 145, pp. 128-136, 2018.

[13] M. G. Azandariani, M. Gholhaki, and M. A. Kafi, "Experimental and numerical investigation of low-yield-strength (LYS) steel plate shear walls under cyclic loading," Engineering Structures, vol. 203, Article ID 109866, 2020.

[14] Y. Suo, S. Fan, C. Li, S. Zeng, and C. Liu, "Parametric analysis on hysteresis performance and restoring force model of LYP steel plate shear wall with two-side connections," International Journal of Steel Structures, vol. 20, no. 6, pp. 1960-1978, 2020.

[15] A. Arabzadeh and H. R. Kazemi Nia Korrani, "Numerical and experimental investigation of composite steel shear wall with opening," International Journal of Steel Structures, vol. 17, no. 4, pp. 1379-1389, 2017.

[16] M. Bypour, M. Kioumarsi, and M. Yekrangnia, "Shear capacity prediction of stiffened steel plate shear walls (SSPSW) with openings using response surface method," Engineering Structures, vol. 226, Article ID 111340, 2021.

[17] C. Dou, Z.-Q. Jiang, Y.-L. Pi, and Y.-L. Guo, "Elastic shear buckling of sinusoidally corrugated steel plate shear wall," Engineering Structures, vol. 121, pp. 136-146, 2016.

[18] Q. Cao and J. Huang, "Experimental study and numerical simulation of corrugated steel plate shear walls subjected to cyclic loads," Thin-Walled Structures, vol. 127, pp. 306-317, 2018.

[19] L. Xu, J. Liu, and Z. Li, "Behavior and design considerations of steel plate shear wall with self-centering energy dissipation braces," Thin-Walled Structures, vol. 132, pp. 629-641, 2018. 
[20] J. L. Liu, L. H. Xu, and Z. X. Li, "Development and experimental validation of a steel plate shear wall with self-centering energy dissipation braces," Thin-Walled Structures, vol. 148, Article ID 106598, 2020.

[21] L. H. Xu, J. L. Liu, and Z. X. Li, "Parametric analysis and failure mode of steel plate shear wall with self-centering braces," Engineering Structures, vol. 237, no. 1, Article ID 112151, 2021.

[22] A. Astaneh-Asl, "Seismic behavior and design of composite steel plate shear walls," Steel TIPS Report, Structural Steel Educational Council, Moraga, California, 2002.

[23] Q. Zhao and A. Astaneh-Asl, "Cyclic behavior of traditional and innovative composite shear walls," Journal of Structural Engineering, vol. 130, no. 2, pp. 271-284, 2004.

[24] Y. L. Guo, Q. L. Dong, and M. Zhou, "Tests and analysis on hysteretic behavior of buckling-restrained steel plate shear wall," Journal of Building Structures, vol. 30, no. 1, pp. 31-39, 2009.

[25] Y. L. Guo, M. Zhou, and Q. L. Dong, "Hysteretic behavior of buckling-restrained steel plate shear wall," Engineering $\mathrm{Me}$ chanics, vol. 26, no. 2, pp. 108-114, 2009.

[26] L. Guo, R. Li, Q. Rong, and S. Zhang, "Cyclic behavior of SPSW and CSPSW in composite frame," Thin-Walled Structures, vol. 51, pp. 39-52, 2012.

[27] L. Guo, Q. Rong, B. Qu, and J. Liu, "Testing of steel plate shear walls with composite columns and infill plates connected to beams only," Engineering Structures, vol. 136, pp. 165-179, 2017.

[28] Y. Lu, G. Q. Li, and G. Li, “Slim buckling-restrained steel plate shear wall and simplified model," Advanced Steel Construction, vol. 8, no. 3, pp. 282-294, 2012.

[29] W.-Y. Liu, G.-Q. Li, and J. Jiang, "Mechanical behavior of buckling restrained steel plate shear walls with two-side connections," Engineering Structures, vol. 138, pp. 283-292, 2017.

[30] Y. Du, J. Hao, J. Yu et al., "Seismic performance of a repaired thin steel plate shear wall structure," Journal of Constructional Steel Research, vol. 151, pp. 194-203, 2018.

[31] J.-G. Yu, L.-M. Liu, B. Li, J.-P. Hao, X. Gao, and X.-T. Feng, "Comparative study of steel plate shear walls with different types of unbonded stiffeners," Journal of Constructional Steel Research, vol. 159, pp. 384-396, 2019.

[32] M.-W. Wei, J. Y. R. Liew, M.-X. Xiong, and X.-Y. Fu, "Hysteresis model of a novel partially connected bucklingrestrained steel plate shear wall," Journal of Constructional Steel Research, vol. 125, pp. 74-87, 2016.

[33] M.-W. Wei, J. Y. R. Liew, Y. Du, and X.-Y. Fu, "Seismic behavior of novel partially connected buckling-restrained steel plate shear walls," Soil Dynamics and Earthquake Engineering, vol. 103, pp. 64-75, 2017.

[34] S. Jin, J. Bai, and J. Ou, "Seismic behavior of a buckling-restrained steel plate shear wall with inclined slots," Journal of Constructional Steel Research, vol. 129, pp. 1-11, 2017.

[35] S. S. Jin, S. C. Yang, and J. L. Bai, "Numerical and experimental investigation of the full-scale buckling-restrained steel plate shear wall with inclined slots," Thin-Walled Structures, vol. 144, Article ID 106362, 2019.

[36] P. Tan, Y. Li, G. Y. Li et al., "A kind of buckling-restrained steel plate shear wall with out-of-plane deformation space," vol. 4, China, ZL, Invention Patent, 2015.

[37] Standardization Administration of the People's Republic of China, GB 50205-2001: Code for Acceptance of Construction Quality of Steel Structures, Ministry of Housing and Urban-
Rural Development of the People's Republic of China, Beijing, China, 2001.

[38] Standardization Administration of the People's Republic of China, JGJ/T 101-2015: Specification for Seismic Test of Buildings, Ministry of Housing and Urban-Rural Development of the People's Republic of China, Beijing, China, 2015.

[39] American Institute of Steel Construction, ANSI/AISC 341-10: Seismic Provisions for Structural Steel Buildings, American Institute of Steel Construction, Chicago, IL, USA, 2010. 